\title{
السعة العقلية وعلاقتها بأسلوب الاعتهاد / الاستقلال \\ والتحصيل الأكاديمي لدى طالبات المرحلة المتوسطة \\ ذوات صعوبات التعلم المتفوقات والعاديات
}

\author{
إعداد \\ ه. عزة محمد عبلده حلة \\ أستاذ مساعد قسم علم النفس \\ كلية التربية - جامعة الطائف
}

مجلة بحوث التربية النوعية - جامعة المنصورة

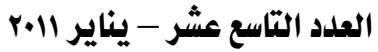




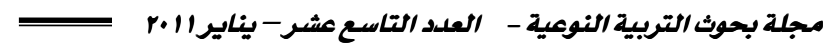

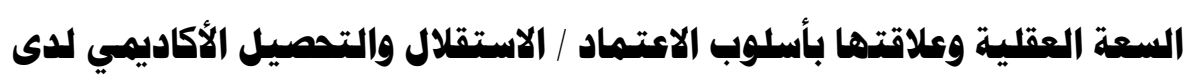 طالبات المرحلة المتوسطة ذوات صعوبات التعلم المتفوقات والعاديات
}

\author{
إعداد \\ د د عزةمحمد عبدهحلة.
}

\section{هقدهة:}

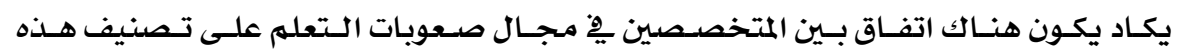

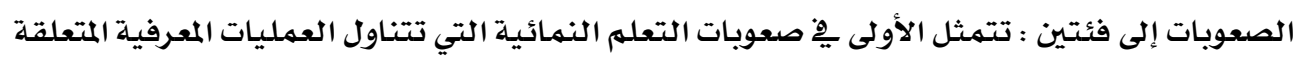

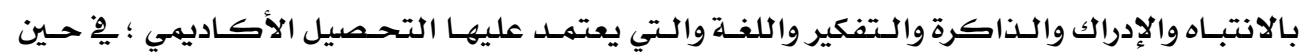

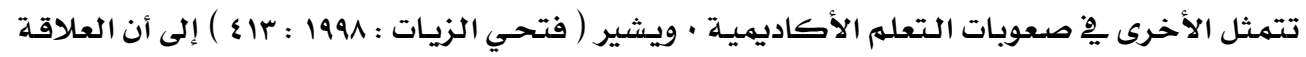

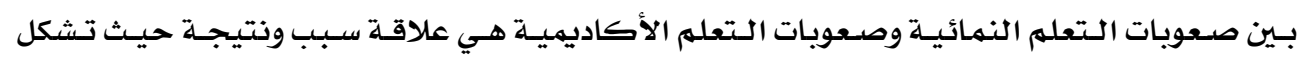

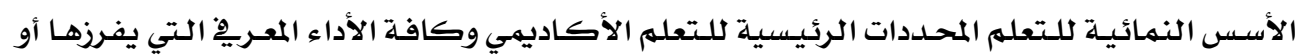

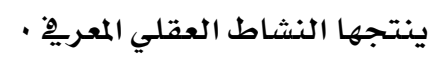

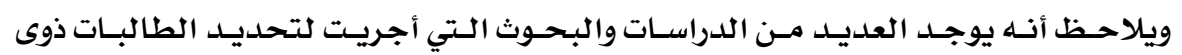

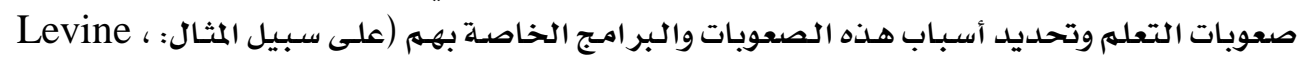

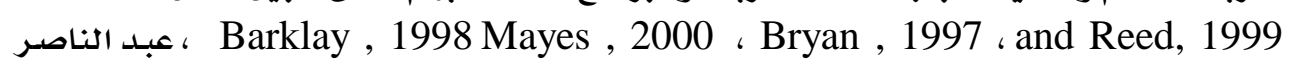

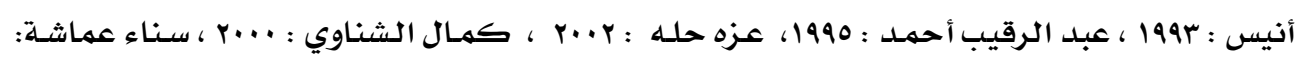

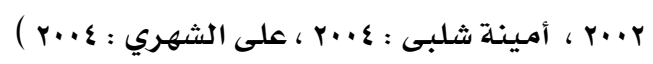

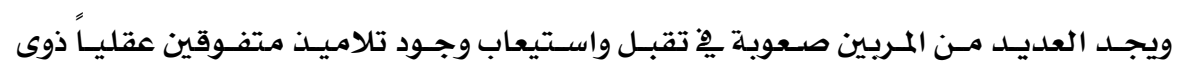

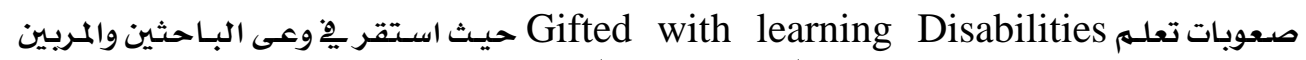

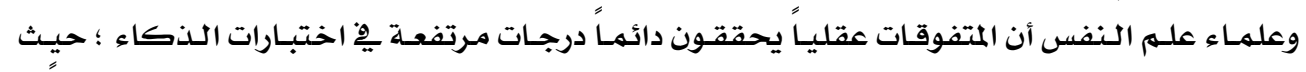

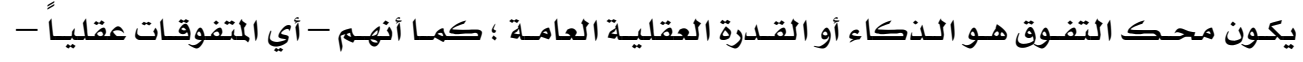

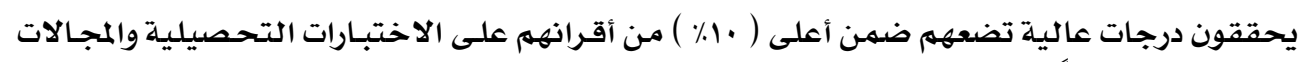

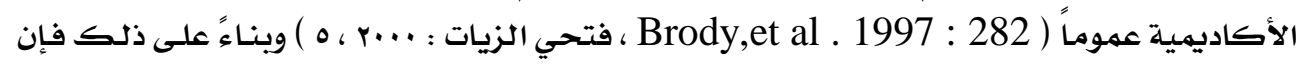

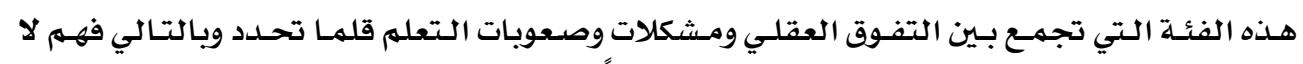

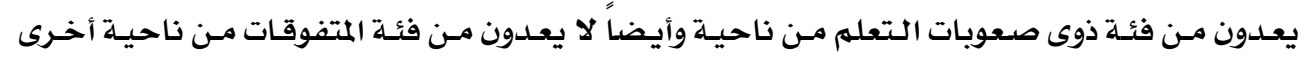

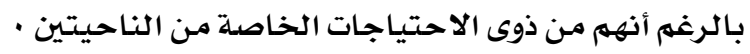

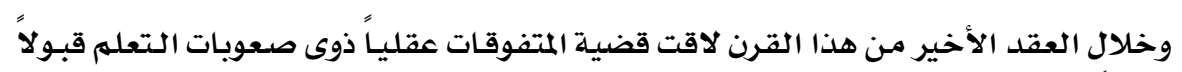

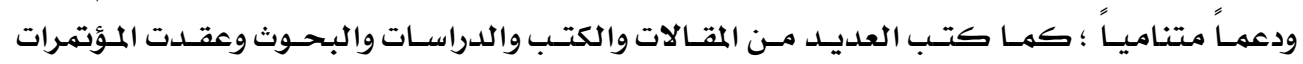


والندوات وكان محورهـا الأساسي هـذا المفهوم الثنائي لغير العاديـة Dual Exceptionality الذي الني

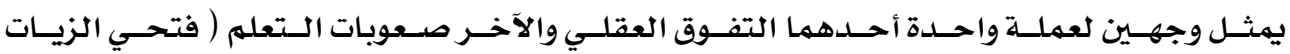
- ( v r a r....

والأسساليب المعرفية تشير إلى الفروق الفردية يِّ طرق تنظيه المعلومـات والخبرات، كمـا أنها

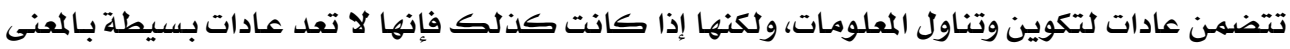

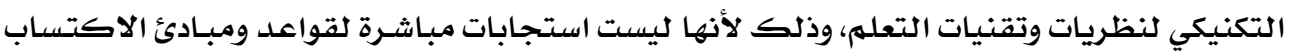

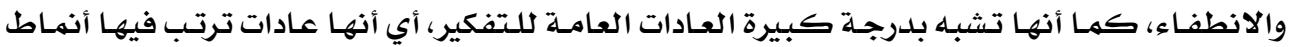

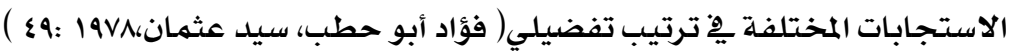

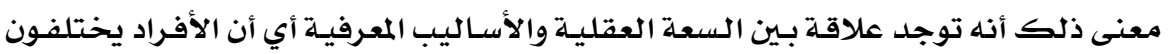

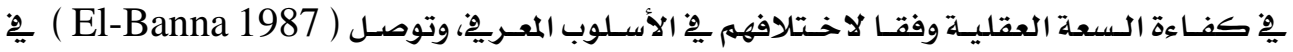

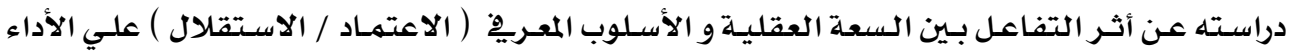

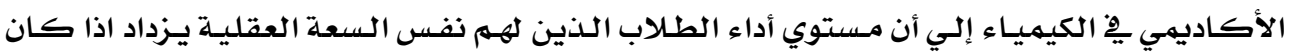

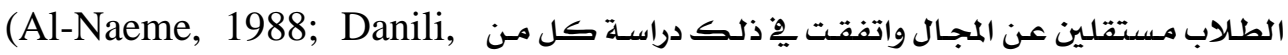
2001)

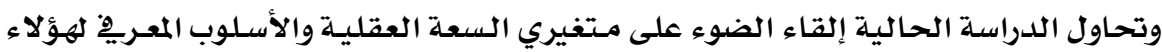

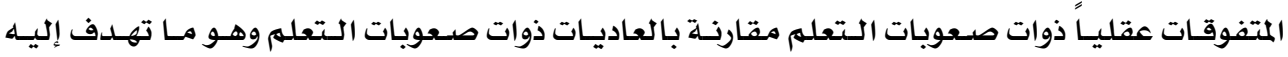

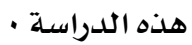

\section{هشكلة الدراسة}

اهتمت الدراسات والبحـوث بالأسـاليب والإجـراءات المستخدمة يِّ تشخيص حـالات صعوبات

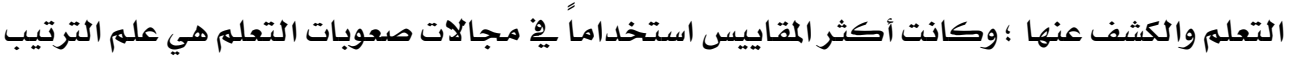

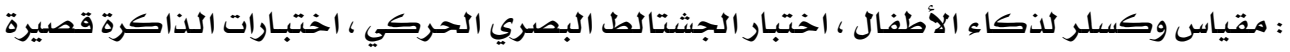

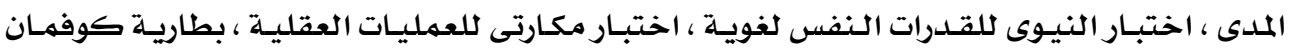

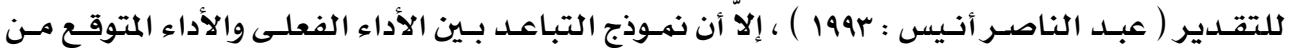
أكثر الأساليب التي اعتمد عليها الباحثون يِّ تشخيص صعوبات التعلى ( Strauser ; Weller , •( Smith , 1988 , Disanto , 1990 Hideman , 19861985 , Rivers ; والمشكلة الأساسـية التي تواجـه المتفوقات عقليـاً ذوات صعوبات التعلهم هي مسكلة التعـرف

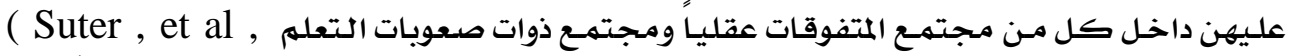

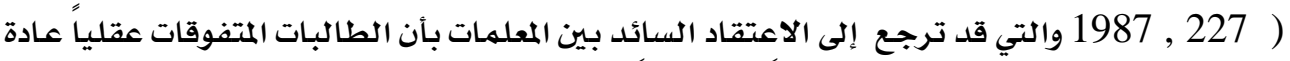

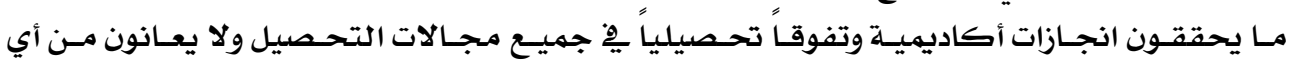

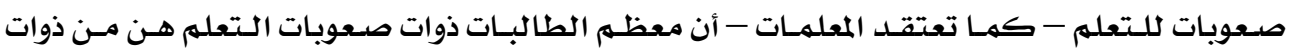

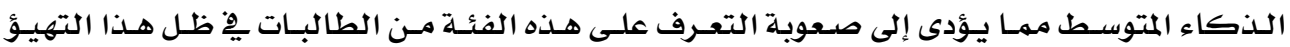

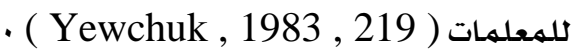




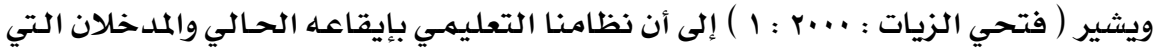

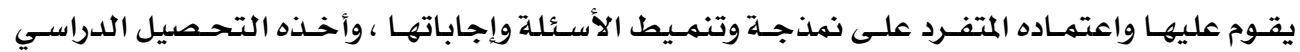

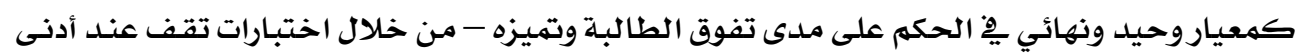

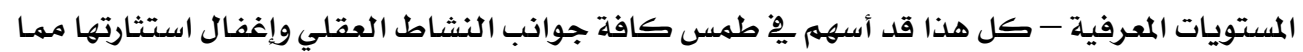

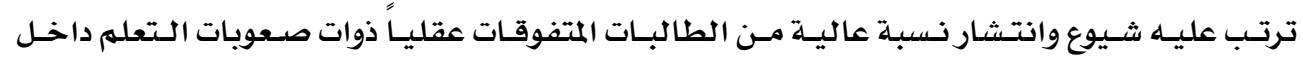

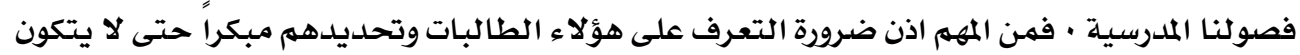

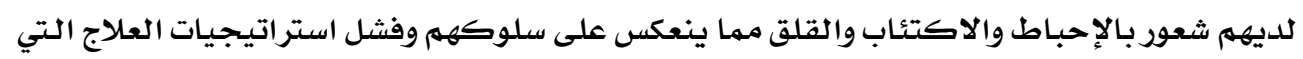

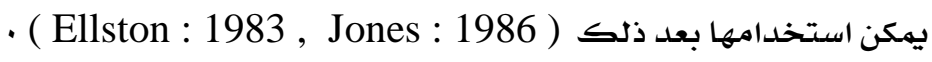

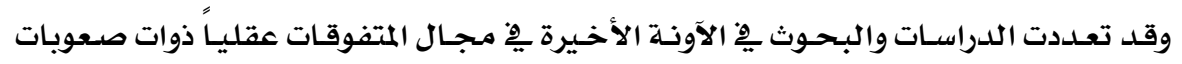

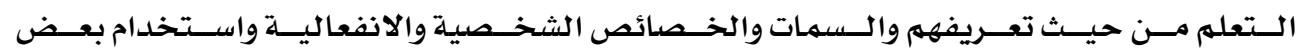

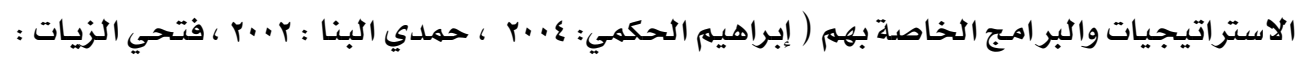
Boodoo et al : 1989 , Baum , 1990 , Brown : 1990 , Ellston : 1993 ، r... - ( , Bees : 1998 , Beckley : 1998

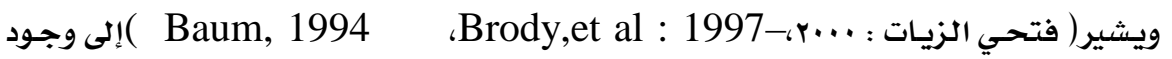

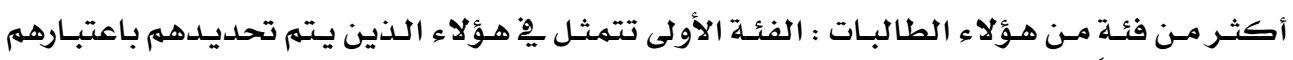

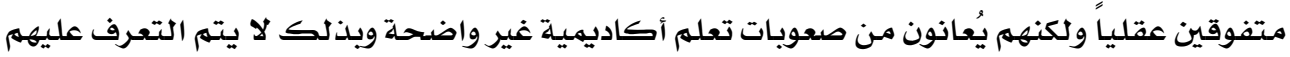

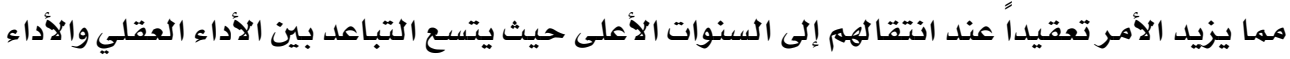

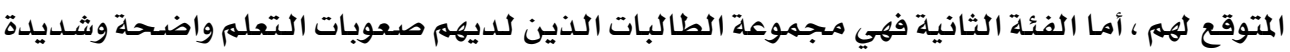

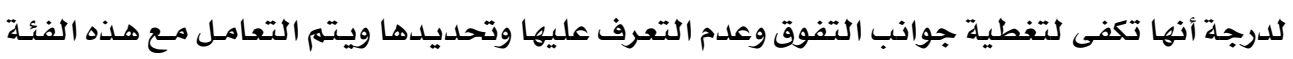

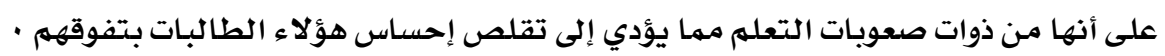

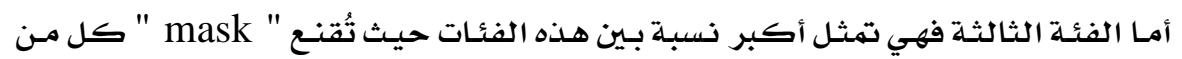

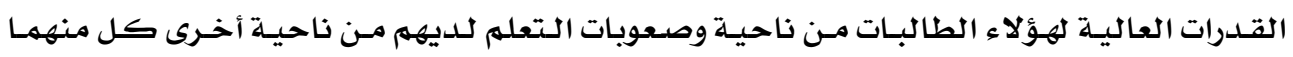

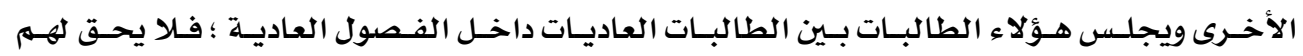

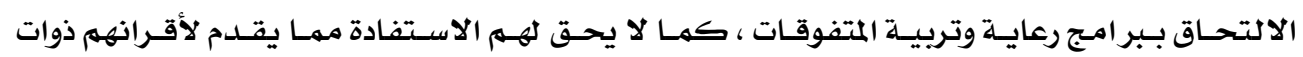

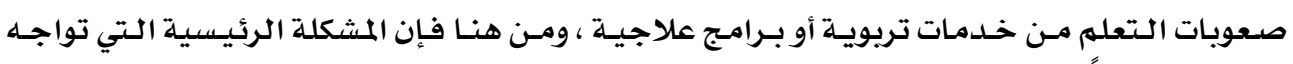

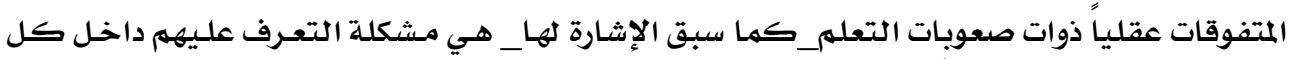
من مجتهـع المتفوقات عقلياً ومجتهمع ذوات صعوبات التعلمات التعلهم. ويعطي مدخل تجهيز المعلومـات Information Processing Approach موجهات عامـة

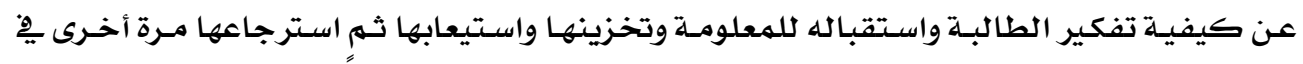

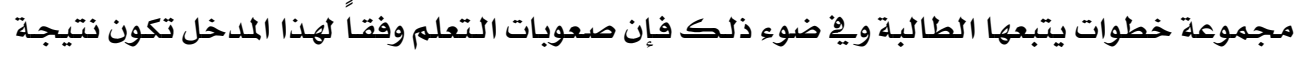

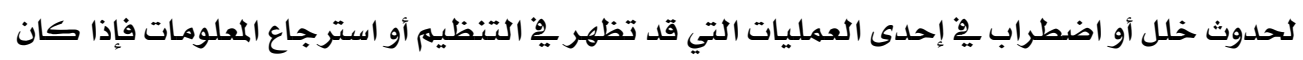

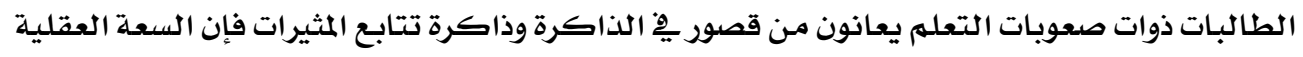




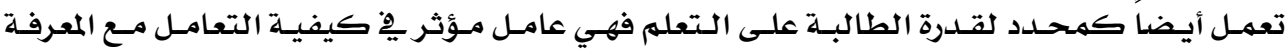

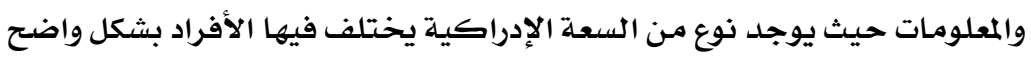

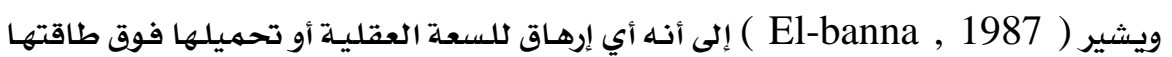

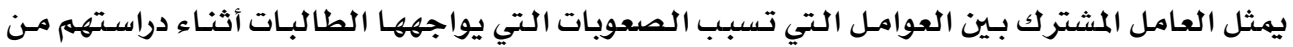

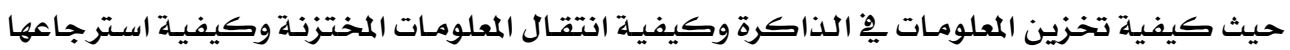

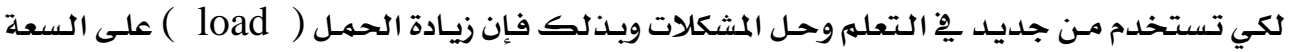

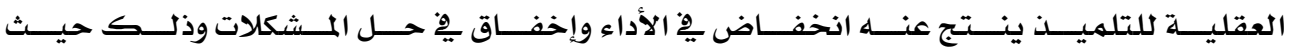

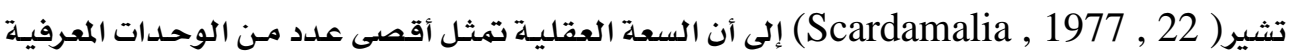

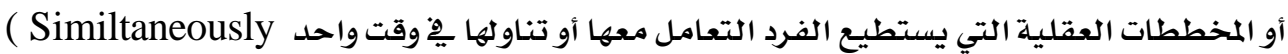

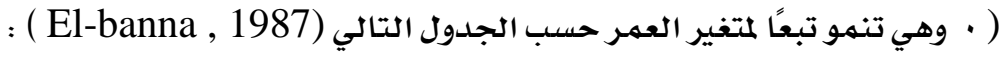

(1) جدول)

جدول يوضح نمو السعة العقلية تبعًا للعمر الزمني.

\begin{tabular}{|c|c|c|}
\hline السعة العقلية & مـراحل بياجيه & العمـر (بالسنـة) \\
\hline$e+1$ & مرحلة قبل العمليـات المبكرة & $\varepsilon-r$ \\
\hline$e+r$ & مرحلة قبل العمليات المتأخرة & $7-0$ \\
\hline$e+r$ & المرحلة المحسوسـة المتقدمة & $\wedge-v$ \\
\hline$e+\varepsilon$ & المرحلة المحسوسـة المتأخرة & 1. -9 \\
\hline $\mathrm{e}+0$ & المرحلة المجرردة المتقدمدة & ir -11 \\
\hline$e+7$ & المرحلة المجردة المتوسطة & Is -14 \\
\hline$e+v$ & المرحلة المجردة المتأخرة & $17-10$ \\
\hline
\end{tabular}

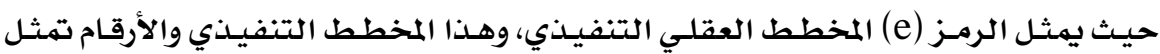

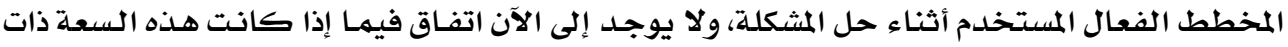

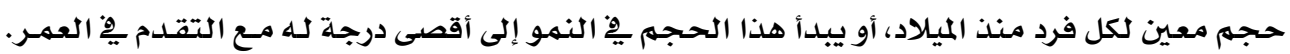

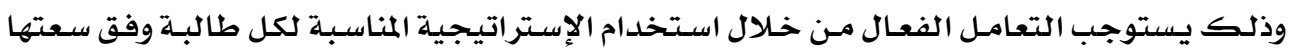

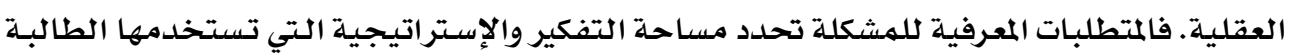

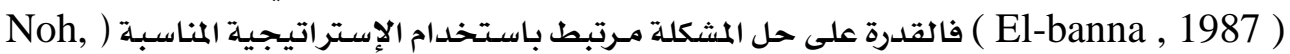

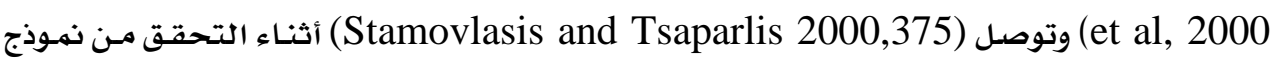
جونستون والبنا التنبؤي إلى ارتباط الإنجاز بسعة الذاكرة العاملة.

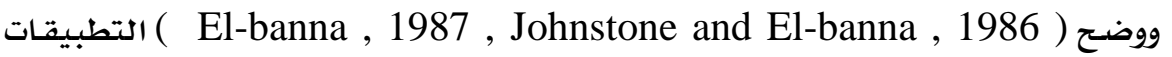

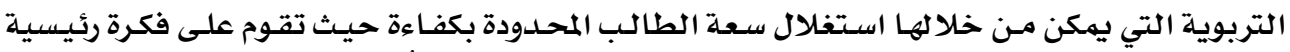

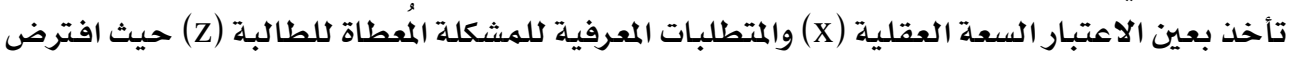




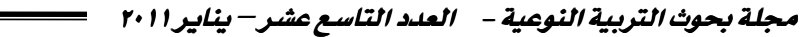

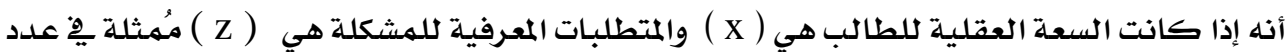

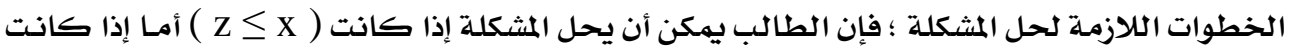

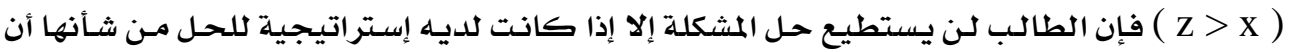

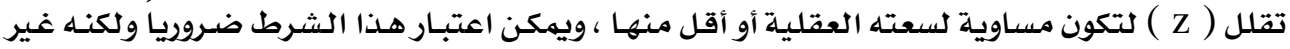

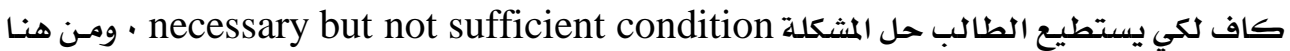

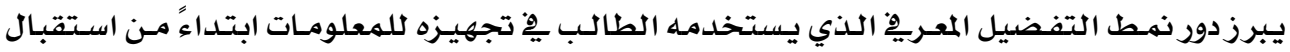

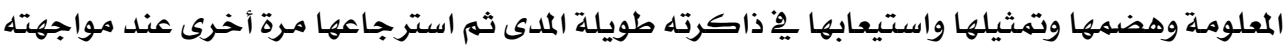
لأي موقف مشكل

ويشير ( إبراهيه الحكمي : ع ·. r ) إلى أن المتفوقات من ذوات صعوبات التعلهم يتمتعن بصفات

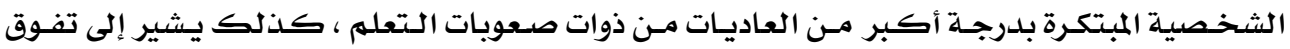

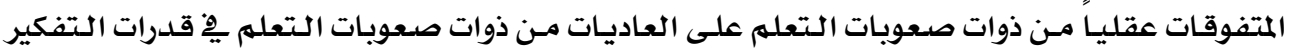

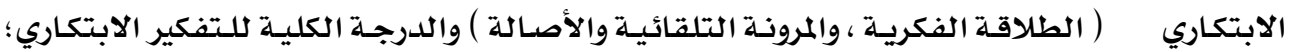

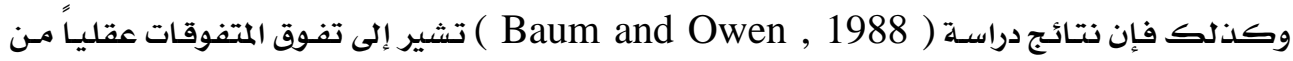

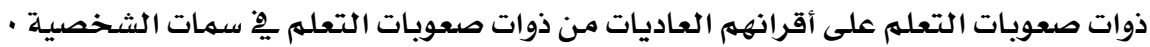
ومن المعلوم أن سرعة وفعالية التعلهم تعتمد على قدرة المتعلهم على إحـداث ارتباطـات جوهريـة

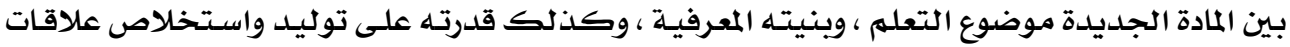

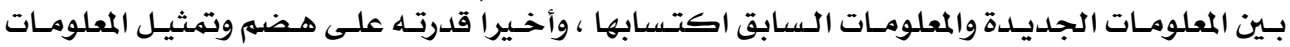

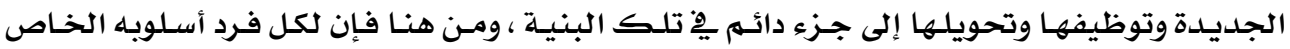

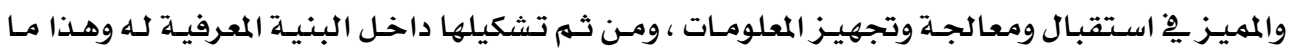

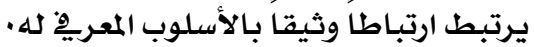

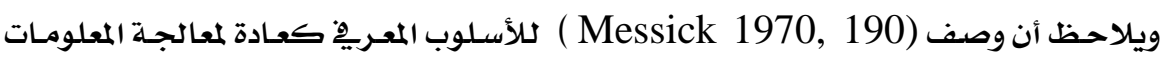

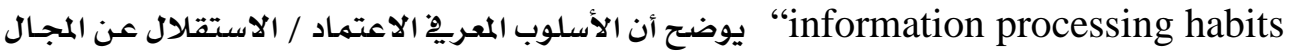

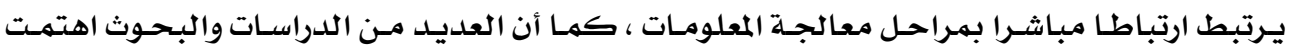

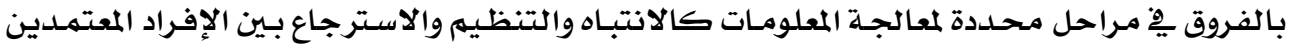
والمستقلين عن المجال \& Berger \& Golberger, 1979; Goodenough, 1976, Davis \& Frank, 1979; Annis,1979; Pierce, 1980; Frank, 1984; Fehrenbach, 1994;

والتي أثارت إلي أن هذه الفروق تؤثر علي أداء الطلاب داخل حجرة الدراسـة . Daniels, 1996)

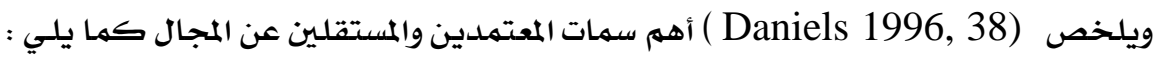

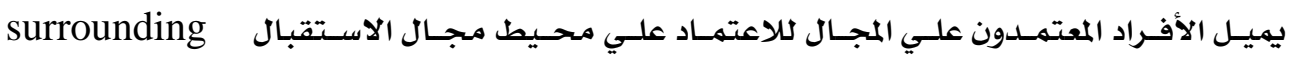

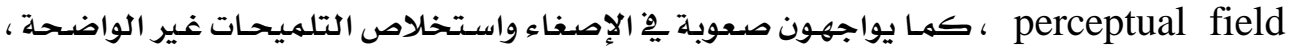

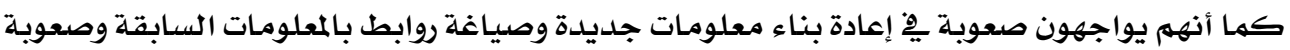

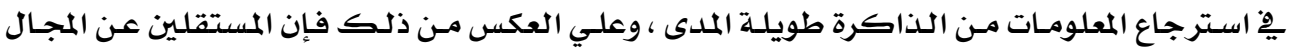




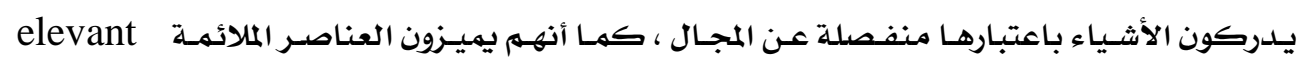

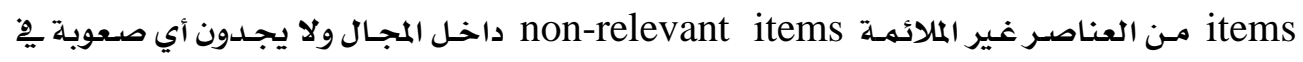
استدعاء أو استرجاع المعلومات من الذاطرة المنائهة طويلة المدىى .

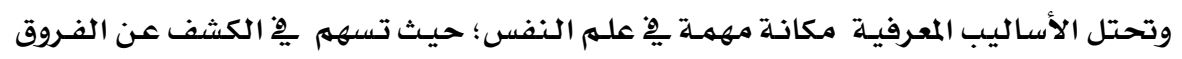

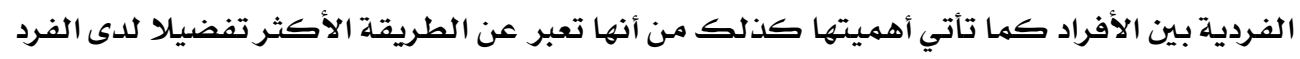

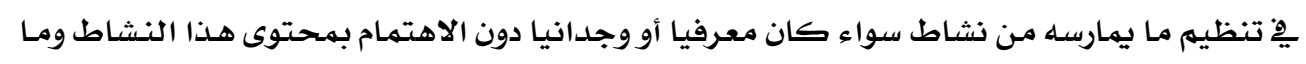

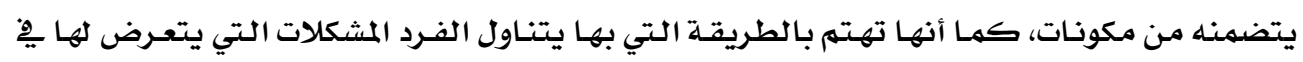
حياته ( أنور الشرقاوي، 1990 : 11 )

و تشير الأساليب المعرفية إلى الفروق الفردية يِّ طرق تنظيم المعلومات والخبرات، كهـا أنها

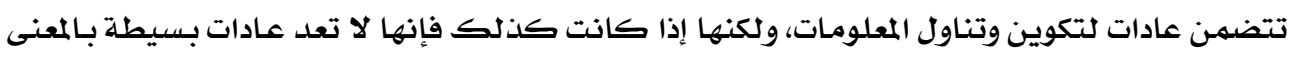

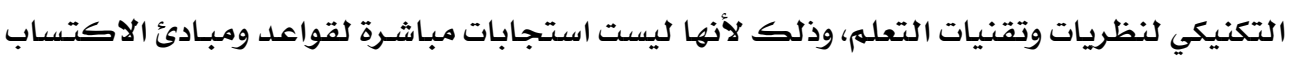

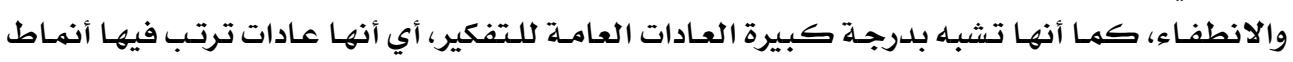

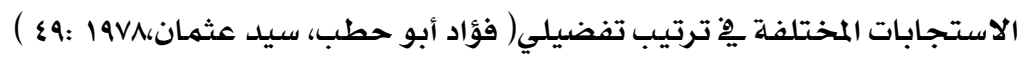

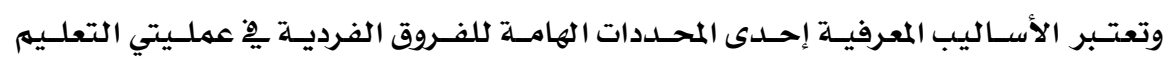

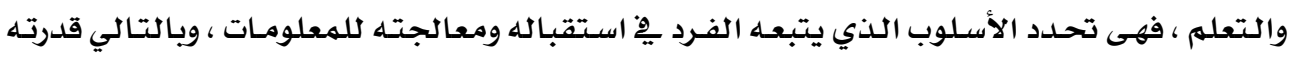

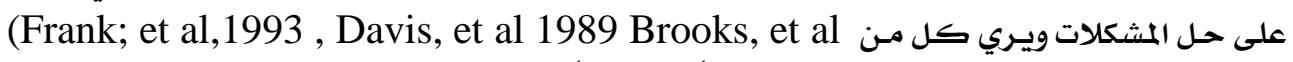

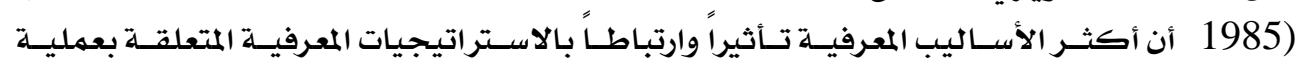

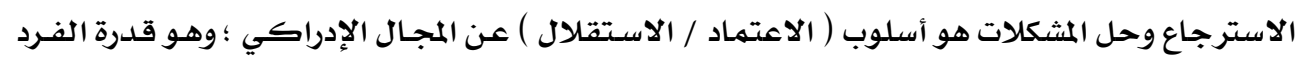

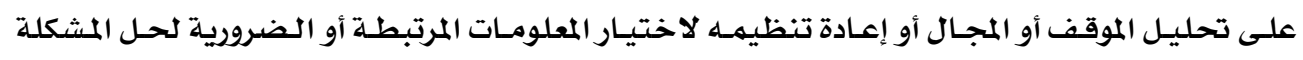

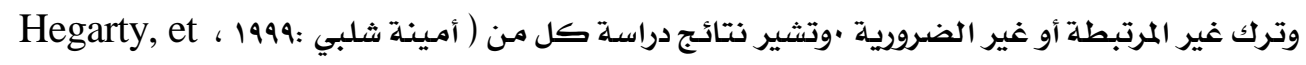

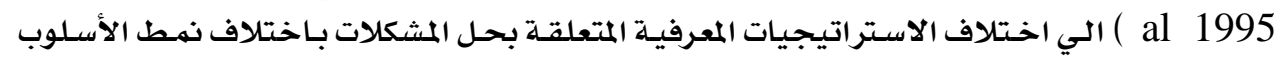

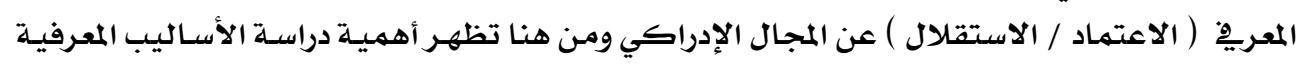

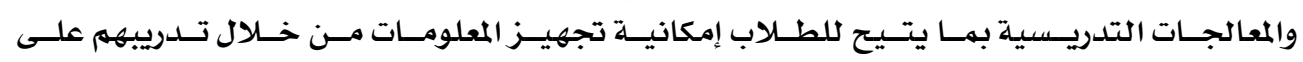

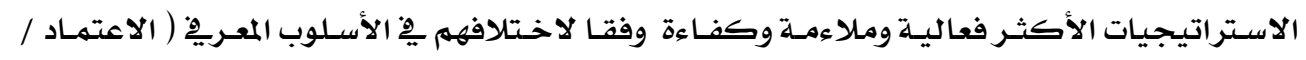

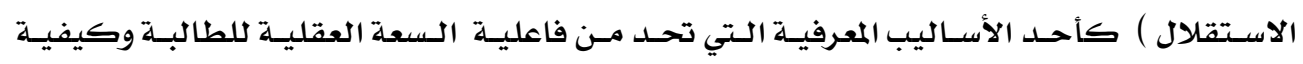

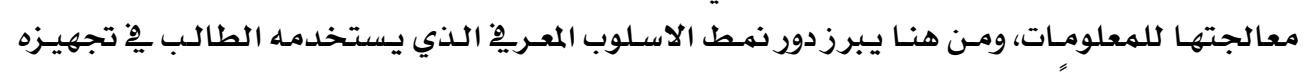

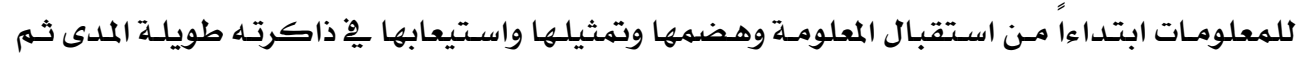

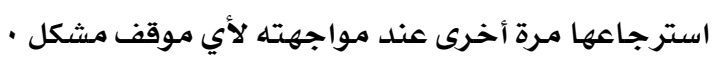

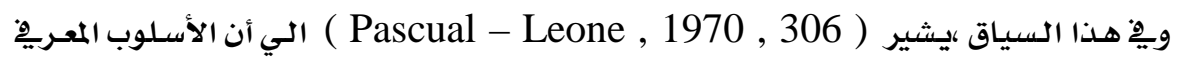

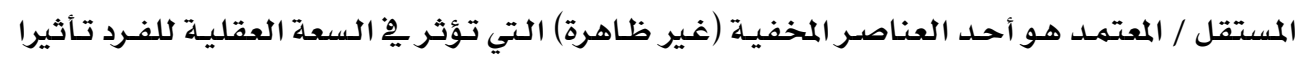

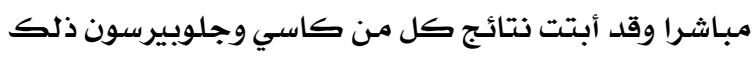


يفرق Witkin and Goodenough , بـين الفرد المعتمـد علي المجال والمستقل

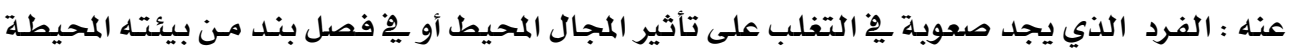

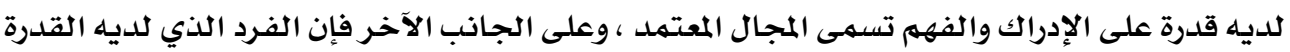

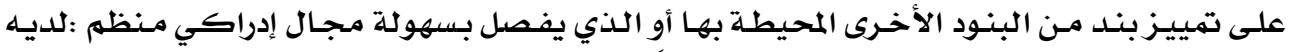

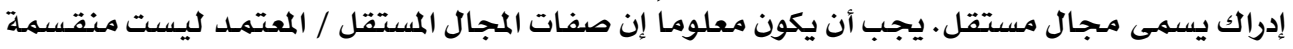

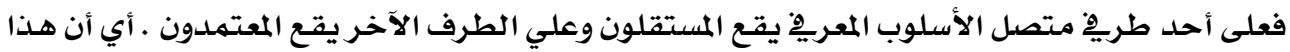

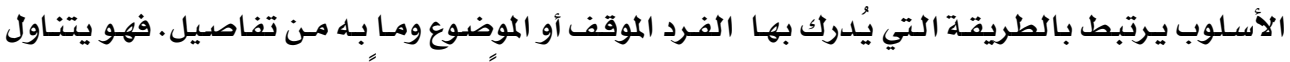

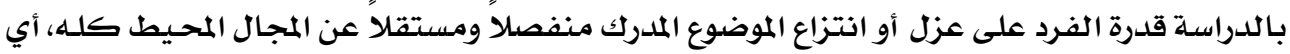

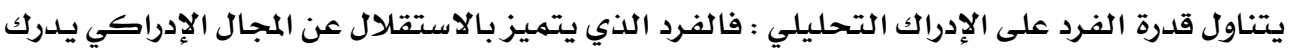

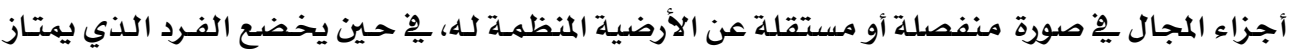

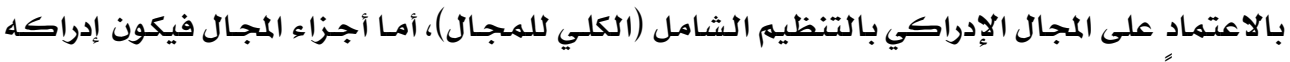
لها مبهما.

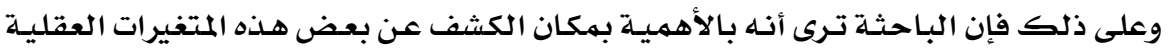

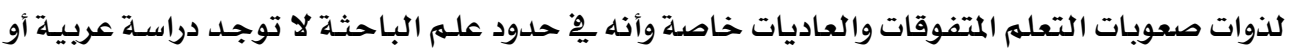

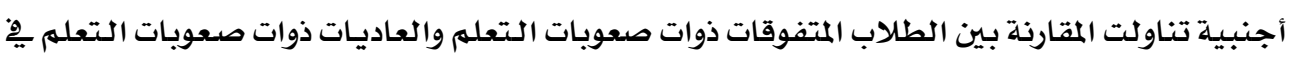

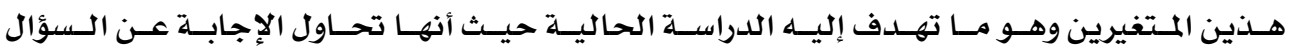
الرئيس التالي : (ملين الميرين

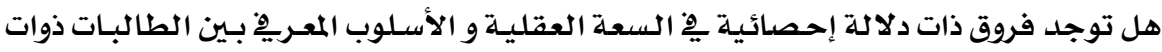

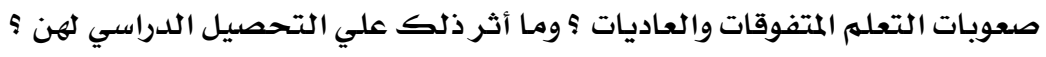
وتتحدد مشكلة الدراسة فِّ التساؤلات الآتية:

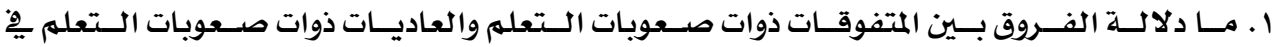

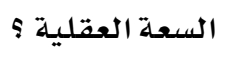

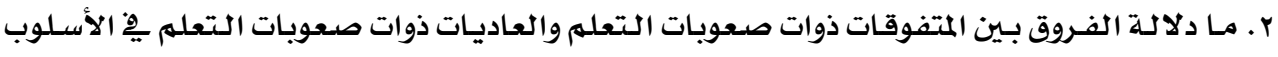

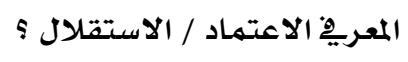

r. ما أثر كل من السعة العقلية و الأسلوب المعربِِ الاعتماد / الاستقلال علي التحصيل الأكاديمي

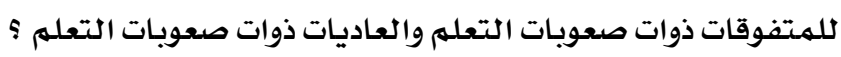

\section{فروض الدوراسة :}

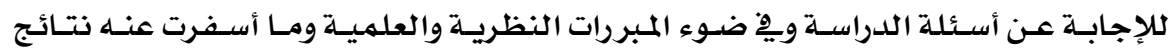

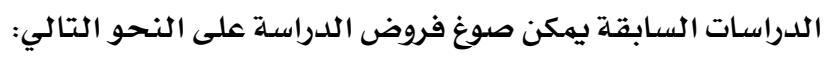

ا ـ لا توجد فروق دالة إحصائيا بين متوسطات رتب درجـات المتفوقات ذوات صعوبات التعلم والعاديات

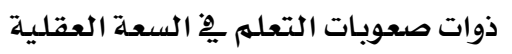


r . لا توجد فروق دالة إحصائيا بين متوسطات رتب درجـات المتفوقات ذوات صعوبات التعلهم والعاديات

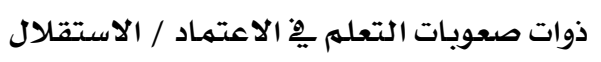

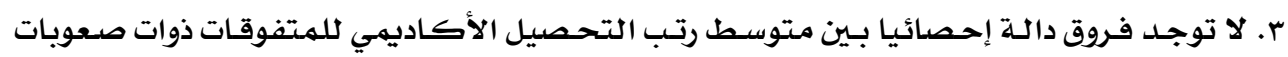

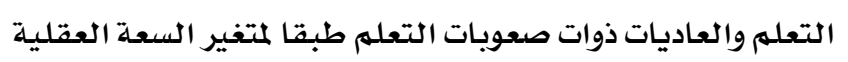

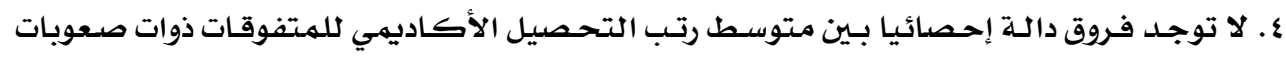

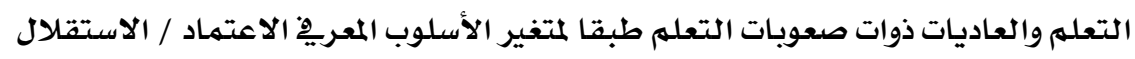

أهداف الدراسة :

تهرف الدراسة الحالية إلى :

ا ـ تحديد نسبـة ذوات صعوبات التعلهم من العاديات والمتفوقات يْ مجتهمع الدراسة الحالية . r ـ التوصل إلى الفروق بين الطالبات ذوات صعوبات التعلهم من العاديات والمتفوقات يِ السعة العقلية. r. التوصل إلى الفروق بين الطالبات ذوات صعوبات التعلم من العاديات والمتفوقات يِّ الأسلوب المعريف

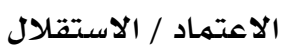

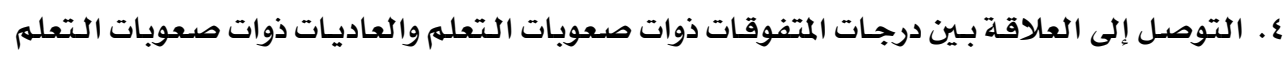

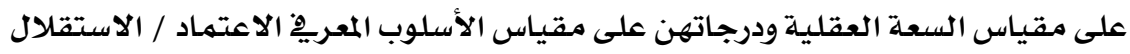

أهميية الدراسة : مقياس الهئ

\section{تتضع أهمية الدراسة الحالية فِ :}

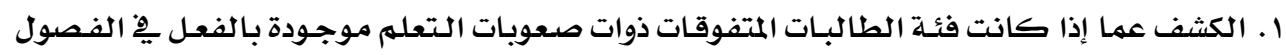

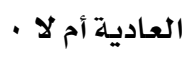

r . تناول فئة الطالبات المتفوقات ذوات صعوبات التعلم بالدراسـة ِِّ بعض المتغيرات العقلية والمعرفية.

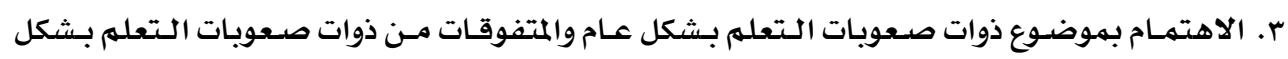

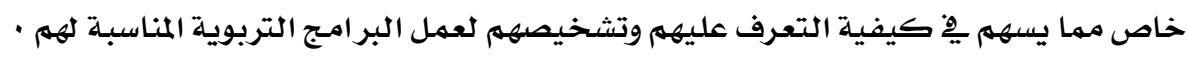

\section{تهديد هصطات الدراسة :}

\section{Gifted student الطالبة المتفوقة -}

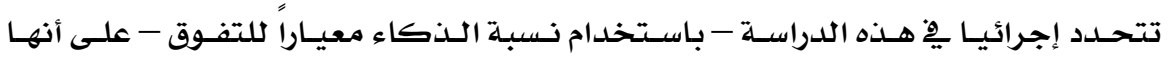

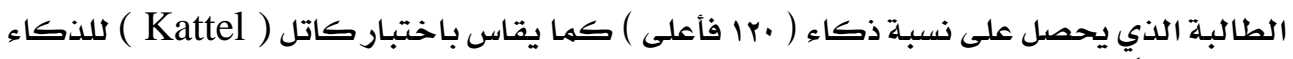

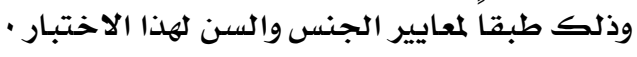

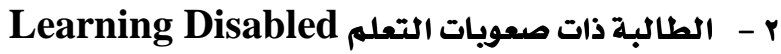

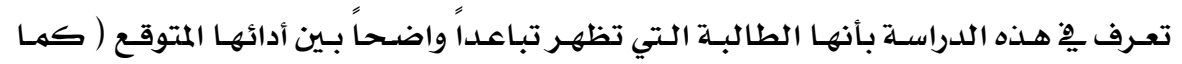

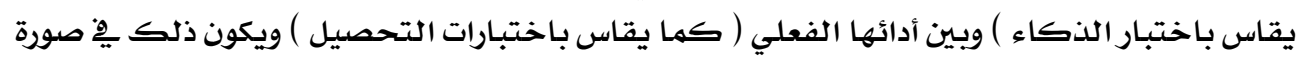




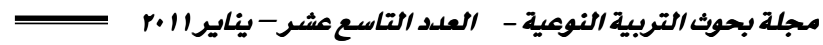

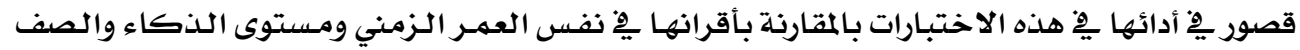

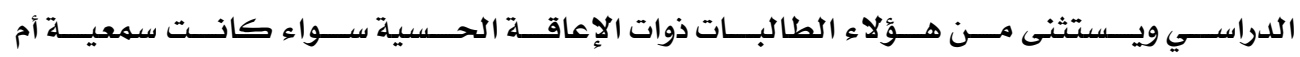
بصرية أم حركية.

يتم تشخيص ذوات صعوبات التعلم يِ الدراسة الحالية على أساس محكين هما: أ - - محك الاستبعاد exclusion criterion

وذلك عن طريق استبعاد الطالبـات من أفراد الصفة مهن تقل نسبـة ذكائهن عن ( . .1 ) مـع

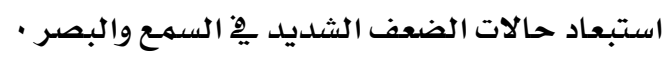
ب - محك التباعد discrepancy criterion

وذلك عن طريق حسـاب التباعد بين الأداء التحصيلي المتوقع ( كهـا يقـاس بـاختبـار كاتل

للذكاء ) والأداء التحصسيلي الفعلي ( كما يقاس بلدرجات الطالبـات يِ الاختبارات المدرسيـة ) -

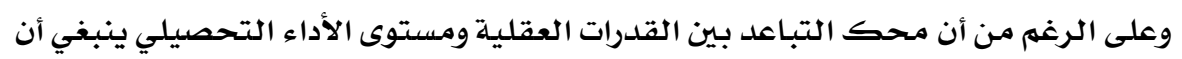
يقاس الأداء التحصيلي فيه بـاختبـار مقنن إلا أن البـاحثة آثرت أن تتناول أداء الطالبـات كما تشخصـه

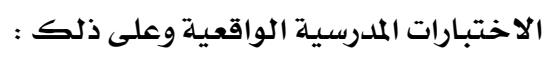

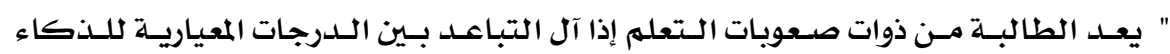

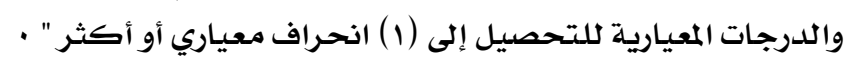

وبـالرغم من وجـود بعض التحفظـات على اسـتخدام مححك التبـاعد أو الانحـراف الدال بـين

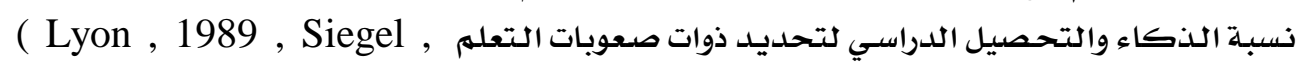
( 1989 إلا أن محك التبـاعد أو الانحراف بين الأداء العقلي والأداء المتوقع أي الانحراف بين القدرات

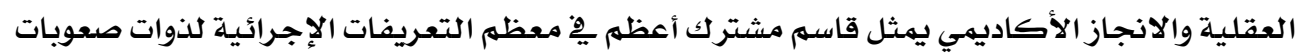

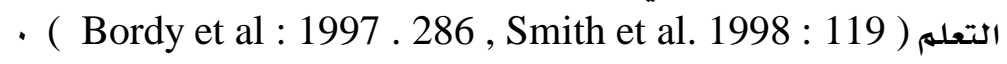

Mental capacity السعة العقلية

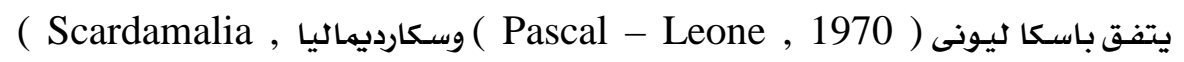

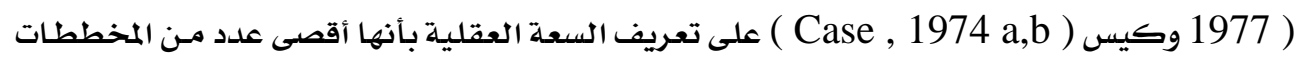

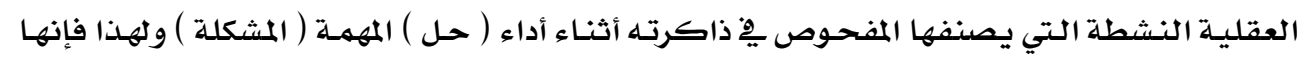

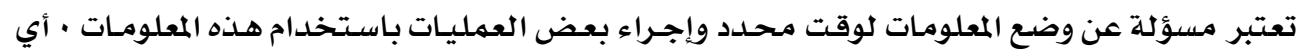

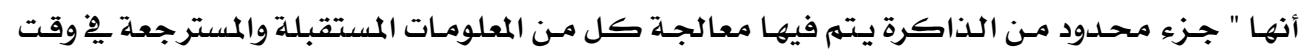

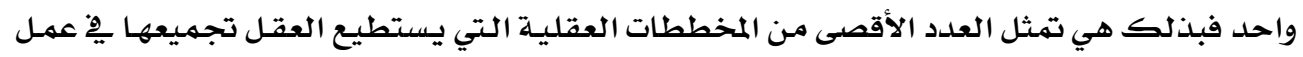

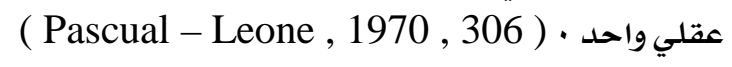




\section{تستخدم الدراسة الحالية الأدوات والمقاييس الآتية :}

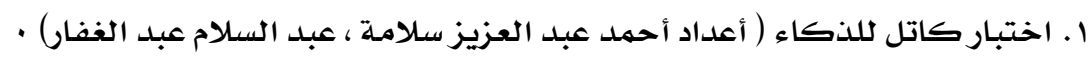

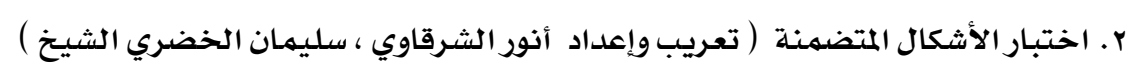

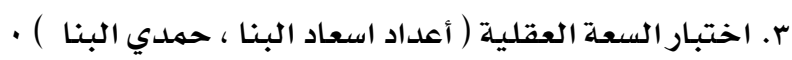

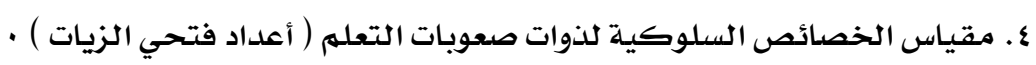

\section{حدود الدراسة :}

\section{اقتصرت الدراسة الحالية على ما يلي :}

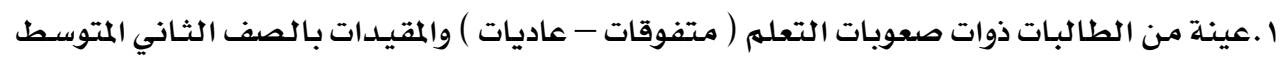
بمدرستين من مدارس الطالبات بمدينة الطائف

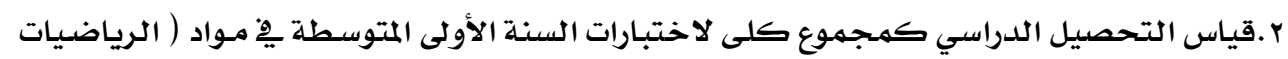

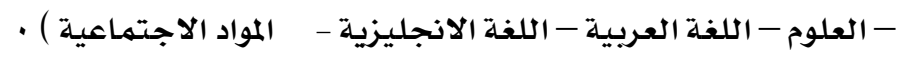

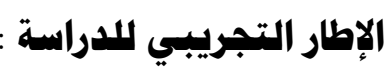

أولاً : اختيار عينة الدراسة

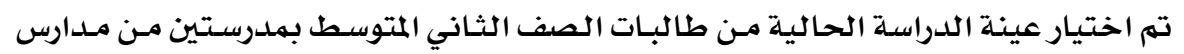

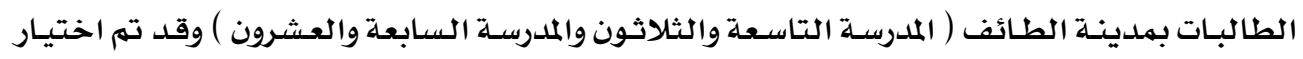

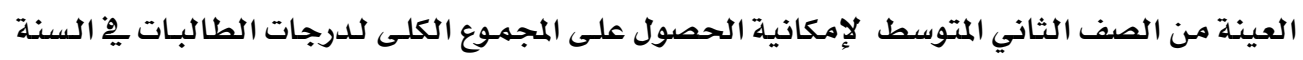

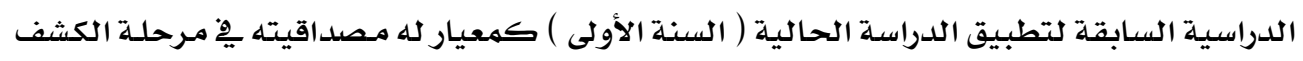

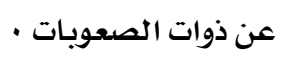

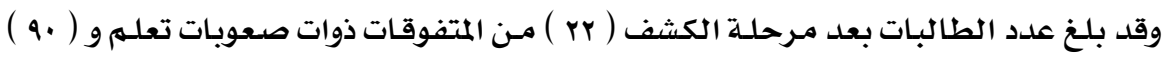

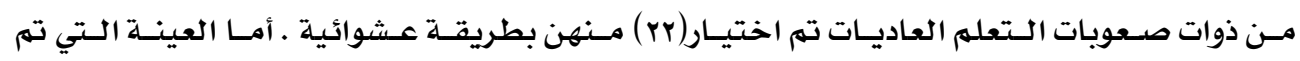

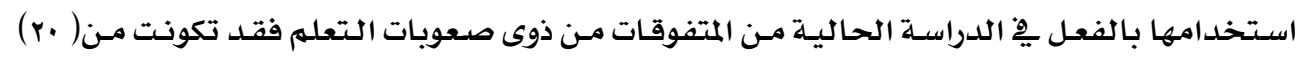

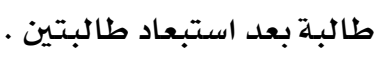

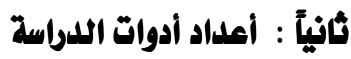
1 - 2 - اختبار كاتل للنكاء

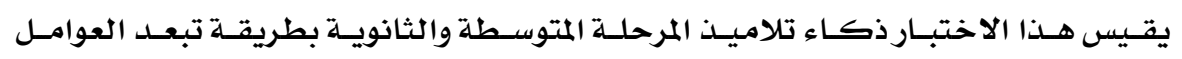

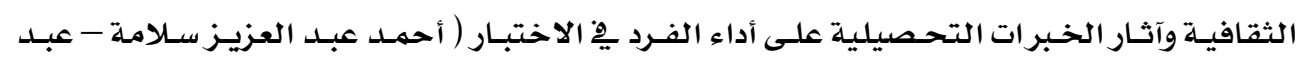

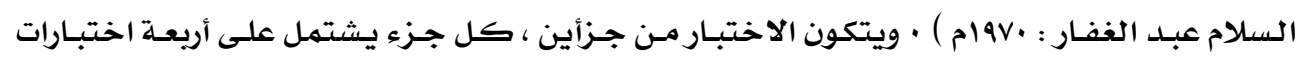

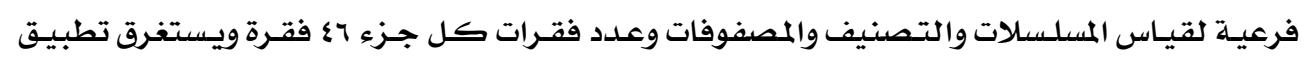




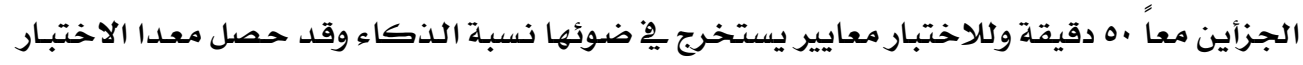

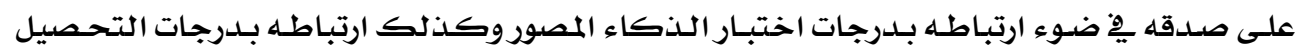

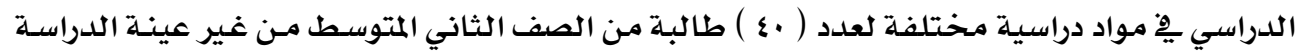

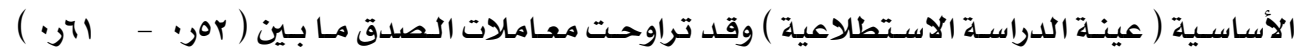

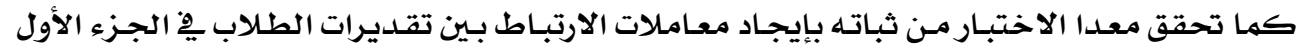

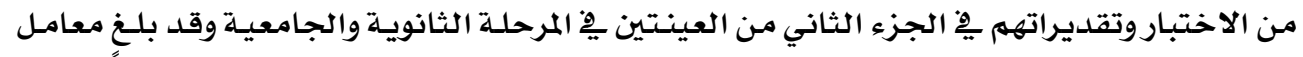

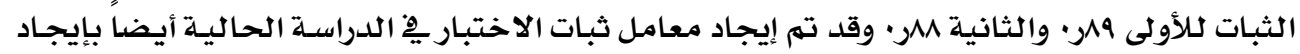

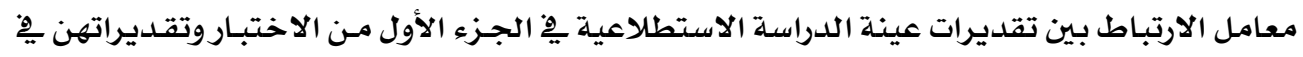

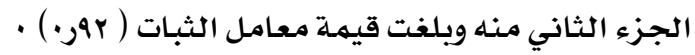

r - مقياس الخصائص السلوكية لذوات صعويات التعلم

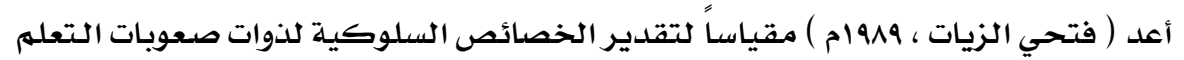

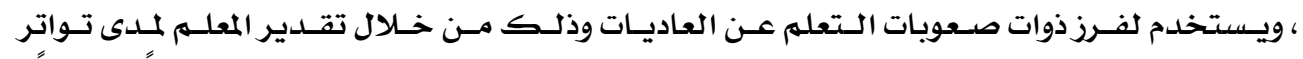

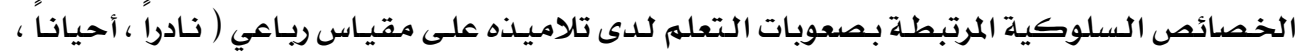

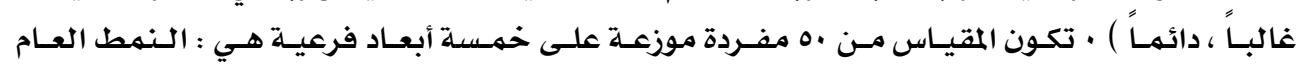

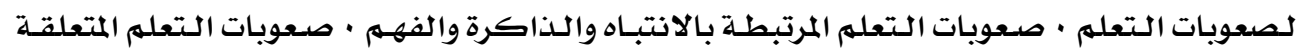

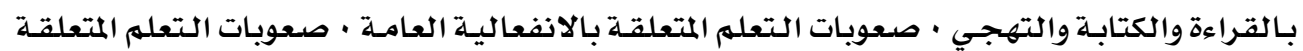

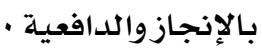

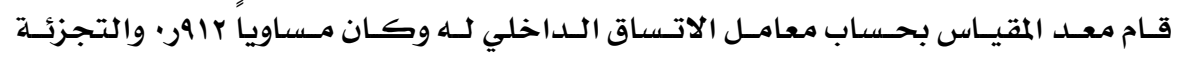

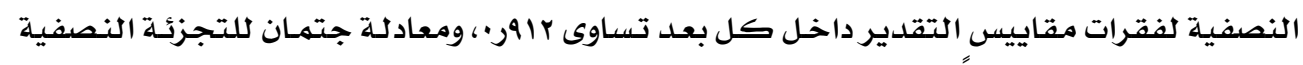

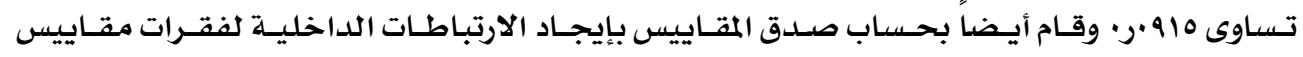

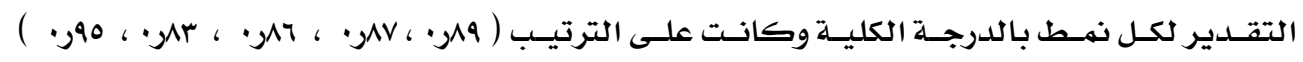

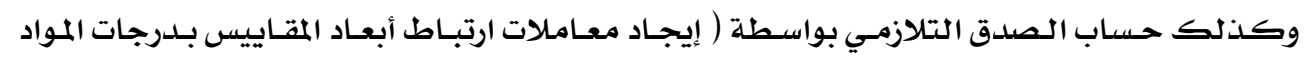

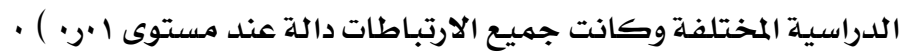
وِِِ الدراسة الحالية تم تقنيين المقياس بالتطبيق على عينة الدراسـة الاستطلاعية بواسطة

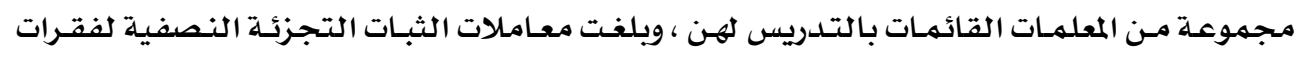

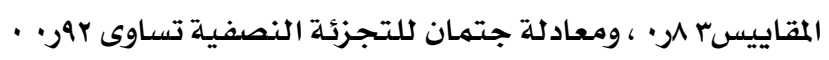

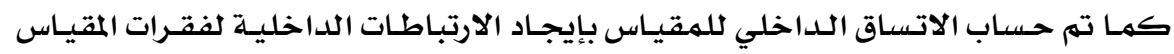

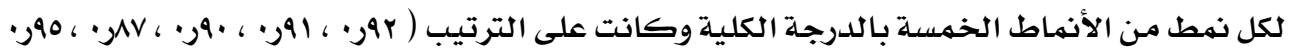

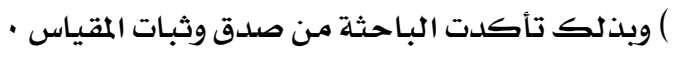


قامت الباحثة باستخدام اختبار الأشكال المتقاطعة لجان باسكاليونى F.I.T. Figural )

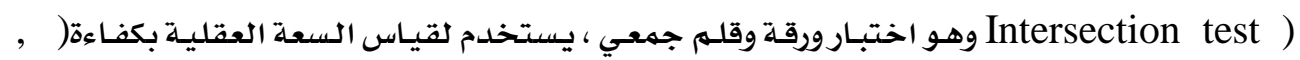
(Case , 1974 Scardamalia , 1970 , , Pascual - Lone 1977

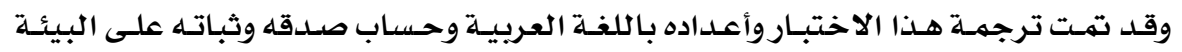

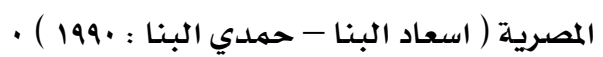

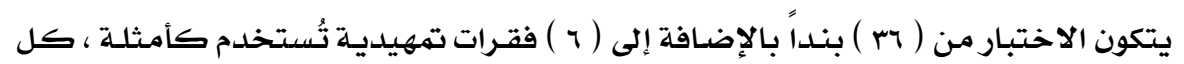

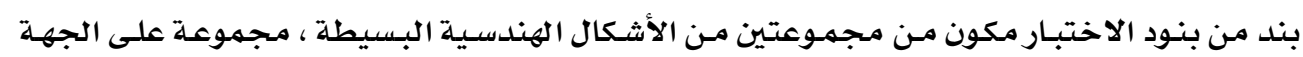

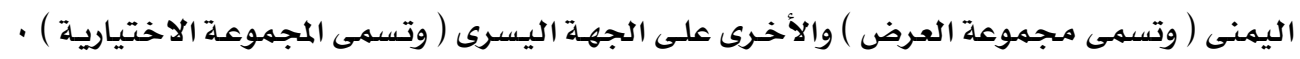

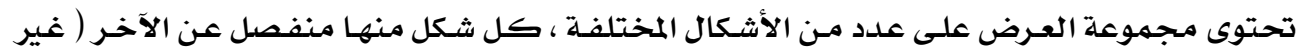

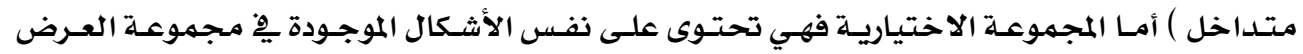

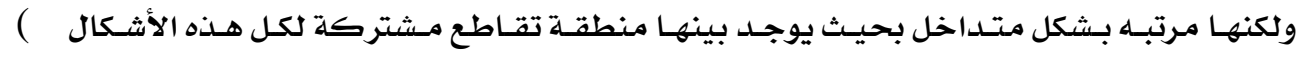
common are of intersection )

الأشكال كما ِِِ المثال التالي :
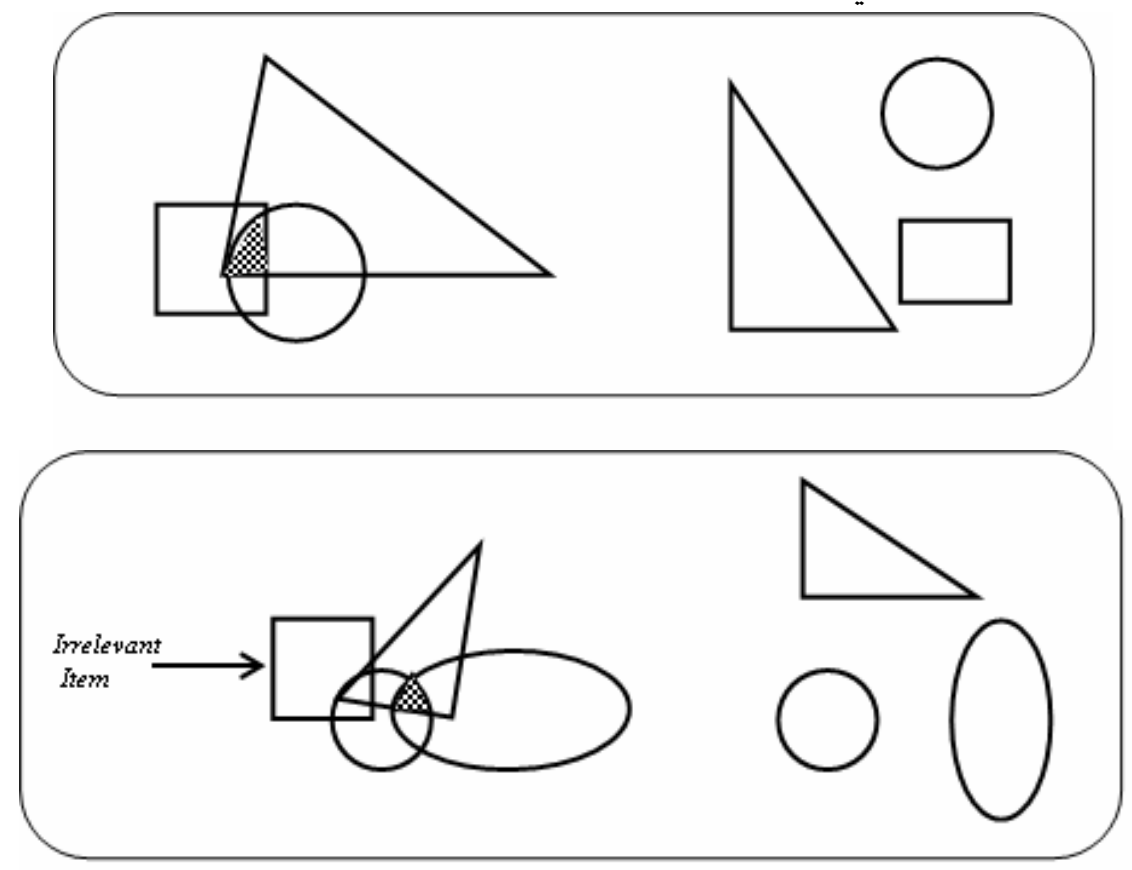

وتحتوي كل مجموعة مـن الأشكال على فئكات يمكن تمثيلها بعـدد الأشـال . ويهكن تمثيل

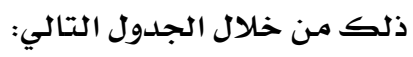




\section{جدول (£):}

فئات اختبار السعة العقلية.

\begin{tabular}{|c|c|}
\hline | عدد الأسئلة & الفئة (عدد الأثكال)| \\
\hline \hline 0 & $r$ \\
\hline 0 & $r$ \\
\hline$\gamma$ & $\varepsilon$ \\
\hline 0 & 0 \\
\hline 0 & $r$ \\
\hline 0 & $\checkmark$ \\
\hline 0 & $\wedge$ \\
\hline
\end{tabular}

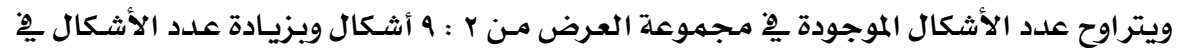

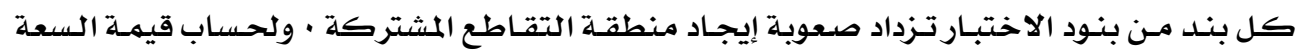

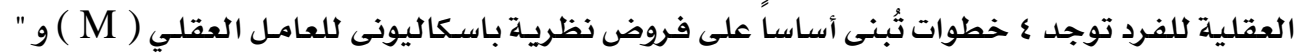

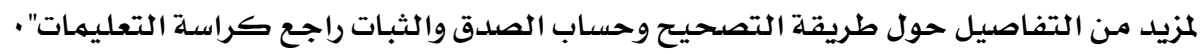

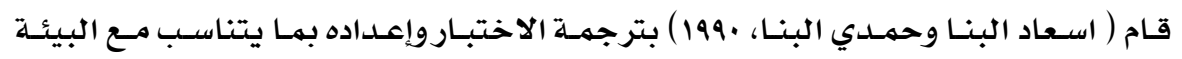

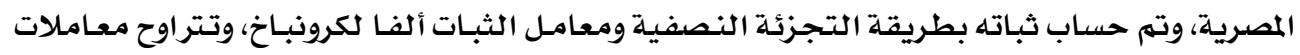

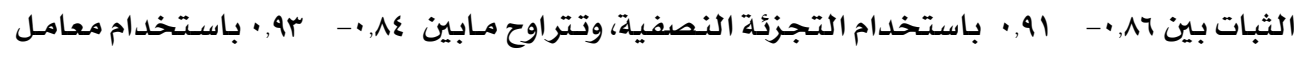

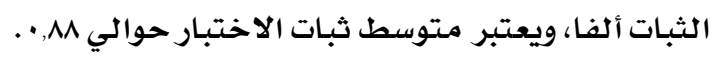

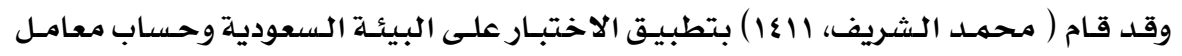

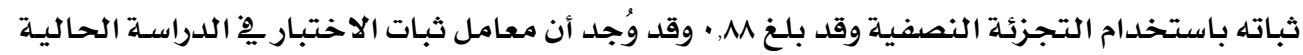

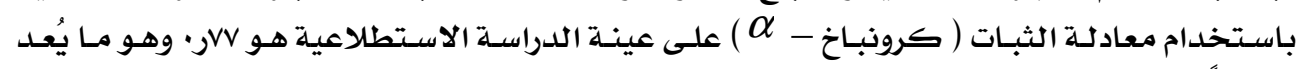

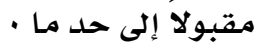

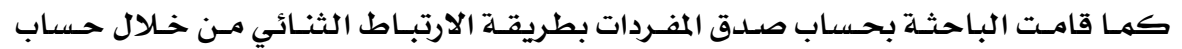

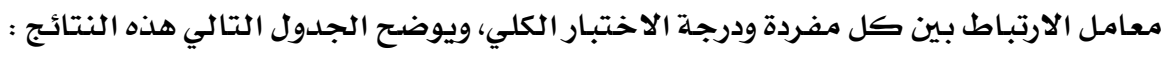




\section{جدول (0)}

معامل ارتباط المفردات بالدرجة الكلية لاختبار السعة العقلية.

\begin{tabular}{|c|c|c|c|}
\hline الدرجـة الكلية & المفردات & الدرجة الكلية & المفردات \\
\hline$\cdot, \cdot 11$ & 19 & - & 1 \\
\hline$\cdot$, Y10 & r. & - & $r$ \\
\hline •, हYq & rI & rr. & $r$ \\
\hline$\cdot$ & $r r$ & - & $\varepsilon$ \\
\hline$\cdot$, YAY & rr & rr. & 0 \\
\hline - & $r \xi$ & $\cdot, \cdot 11$ & 7 \\
\hline$\cdot$ & ro & $\cdot, \cdot 7 \xi$ & $r$ \\
\hline *, ovo & YY & •,ZYV & $\Lambda$ \\
\hline$\cdot, r 00$ & $r V$ & $\cdot$ & 9 \\
\hline$\cdot$ & $r A$ & $\cdot, r \cdot r$ & 1. \\
\hline$\cdot, 194$ & $r q$ & $\cdot, Y M I$ & 11 \\
\hline . & $r$. & . & ir \\
\hline$\cdot, 191$ & rI & $\cdot$, EYV & ir \\
\hline$\cdot, r 00$ & rr & $\cdot$ & 18 \\
\hline$\cdot, \cdot 90$ & rr & *,ovo & 10 \\
\hline$\cdot, r \cdot r_{-}$ & 34 & $\cdot, \cdot 11$ & 17 \\
\hline \multirow[t]{2}{*}{$\cdot, \cdot 11$} & 35 & $\cdot, r+\Lambda$ & iv \\
\hline & 36 & & 18 \\
\hline
\end{tabular}

\section{ع - اختبار الأثكال المتضمنة :}

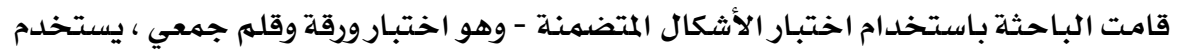

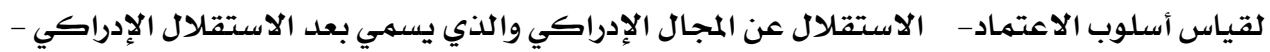

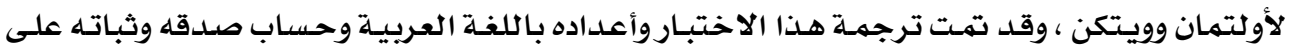

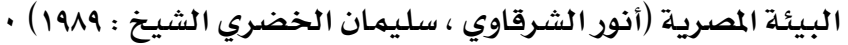

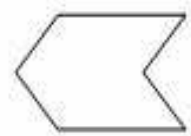

Shape to find

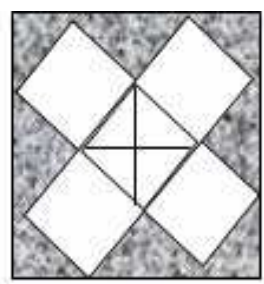


ثالقًاً : إجراءات الدراسة :

تم تطبيق الدراسة الحالية من خلال مرحلتين كما يلي :

المرحلة الأولى : تصنيق

وهي مرحلة التشخيص لتحديد الطالبات المتفوقات والعاديات ذوى صعوبات التعلمه وتم مـن

خلال الخطوات التالية :

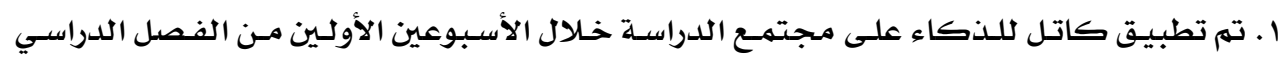

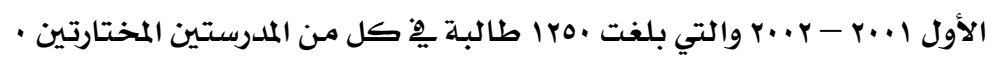

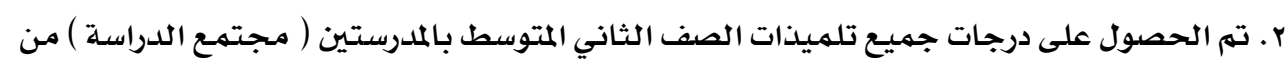

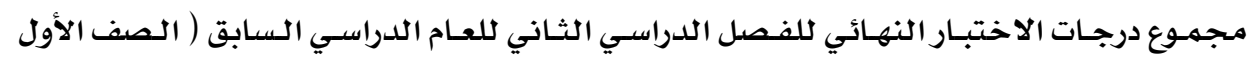

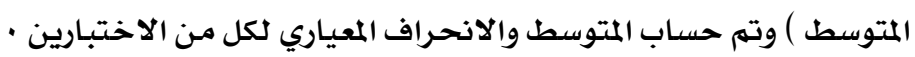

r. تم تشخيص الطالبات ذوات صعوبات التعلهم على أساس محكين هما :

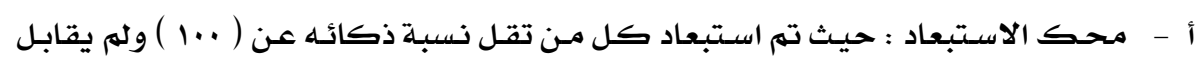

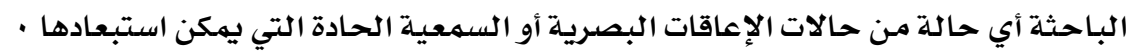

ب - محــك التبـاعـد حيـث تم طـرح درجـة الأداء المتوقـع ( كهـا تم قياسـه باختبـار كاتـل

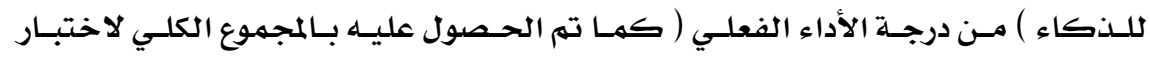

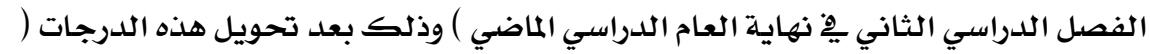

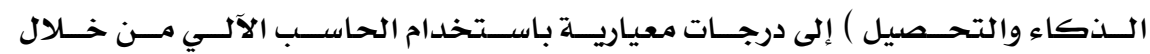

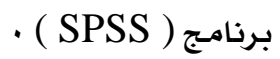

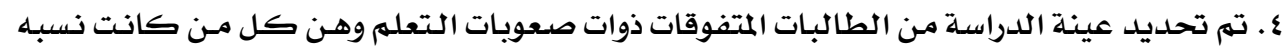

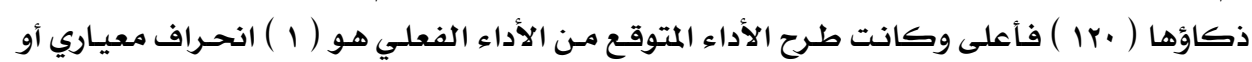

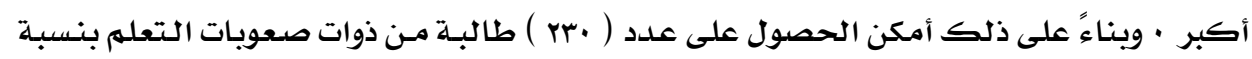

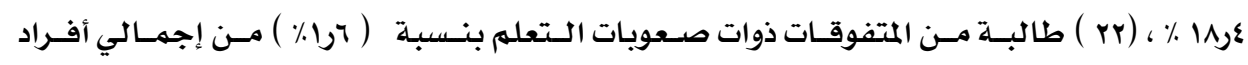

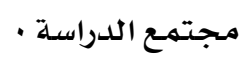

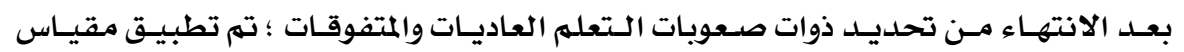

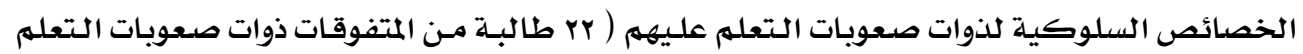

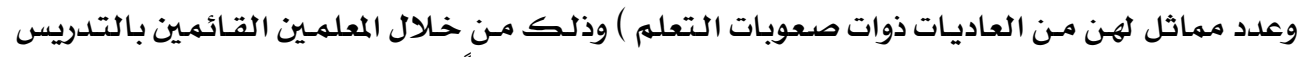

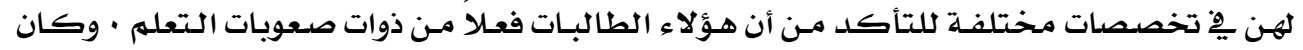

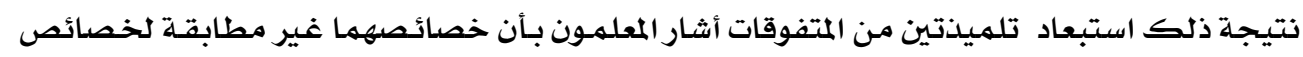

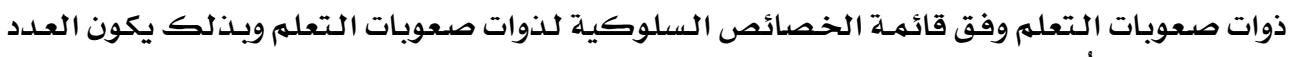

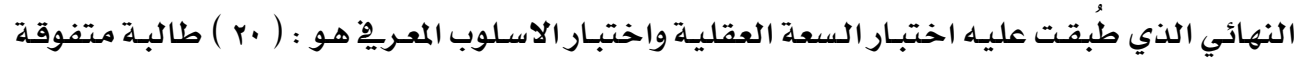

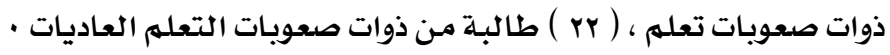


وهي مرحلة تطبيق أدوات قياس متغيرات الدراسة وقد تمت من خلال الخطوات التالية :

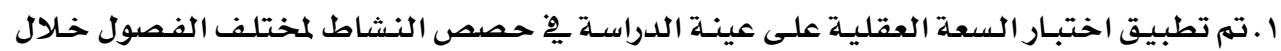

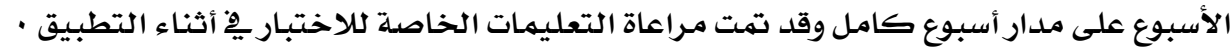

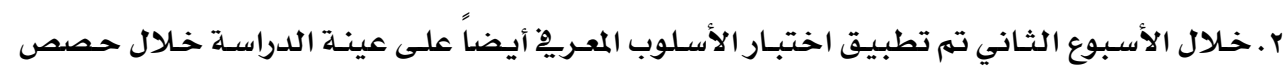

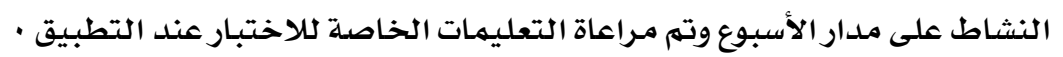

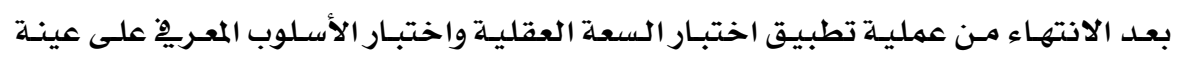

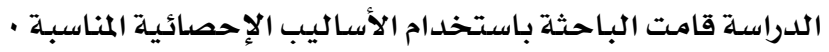
رابعاً : الأساليب الإحصانية المستخدمة : الباستة استخدمت الباحثة معادلـة مـان وتنسى ( Mann Whitney) و اختبـار كروسـكال- والاس Kruskal-Wallis Test

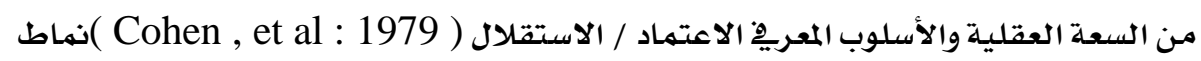

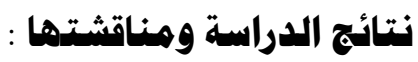

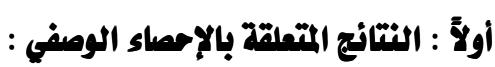
يوضتح جدول (r ) عينة البحث طبقا لمتغيراته بعد تطبيق أدوات البحث .

جدول (r)

عينة البحث طبقا متتغيراته

\begin{tabular}{|c|c|c|c|}
\hline عدد الطالبـات & الفئـة & المجموعة & المتغير \\
\hline ir & س=0 & \multirow{2}{*}{ المتفوقات (·r) } & \multirow{4}{*}{ السعة العقلية } \\
\hline$\checkmark$ & س= & & \\
\hline $1 \xi$ & س=0 & \multirow{2}{*}{ العاديات (rY) } & \\
\hline$\wedge$ & س== & & \\
\hline ir & مستقل & \multirow{2}{*}{ المتفوقات } & \multirow{4}{*}{ الأسلوب المعربِ } \\
\hline$\wedge$ & معتمد & & \\
\hline ir & مستقل & \multirow{2}{*}{ العاديات } & \\
\hline 1. & معتمد & & \\
\hline
\end{tabular}

ثانيا : النتائج المتعاقة بالفرض الأول للدراسة :

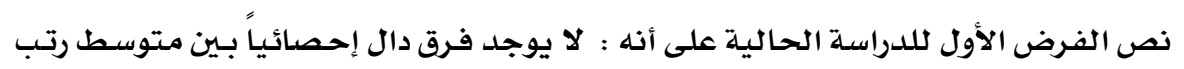

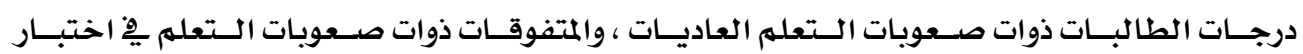
السعة العقلية الطاليـات 


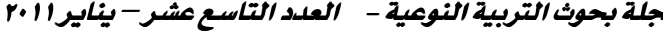

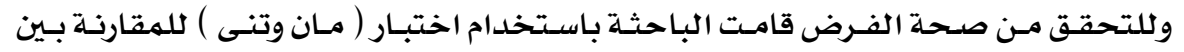

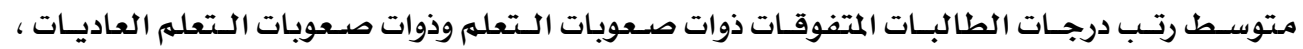

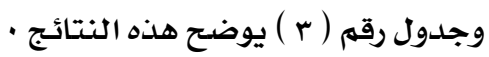

\section{جدول ( ) م )}

الفروق بين العاديات والمتفوقات من ذوات صعوبات التعلم يـ السعة العقلية

\begin{tabular}{|c|c|c|c|c|}
\hline الدلالة & قيمـة " ى & متوسط الرتب & ن & المجموعة \\
\hline \multirow{2}{*}{.0 .0} & \multirow{2}{*}{09,0} & ( & r. & المتفوقات ذوات صعوبات التعلم \\
\hline & & | & rr & العاديات ذوات صعوبات التعلم \\
\hline
\end{tabular}

يتضح من جدول ( r ) أنه يوجد فرق بين متوسط رتب درجـات مجموعة الطالبـات العاديات

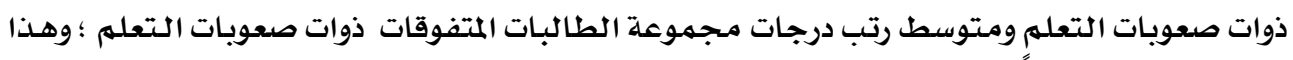

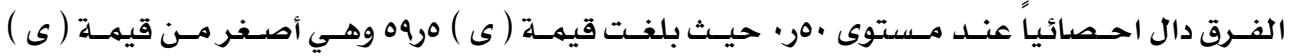

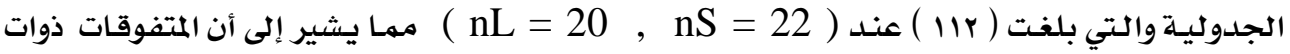

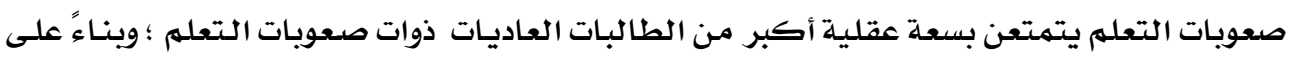

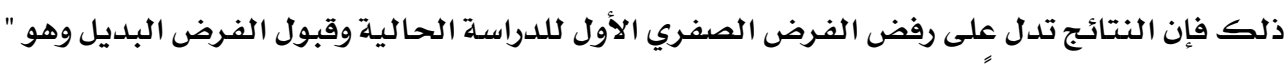

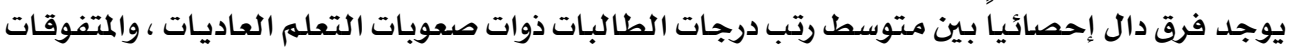

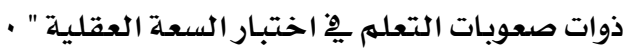

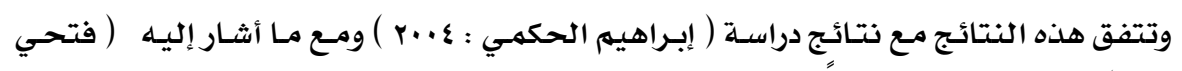

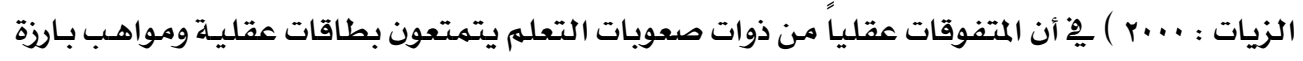

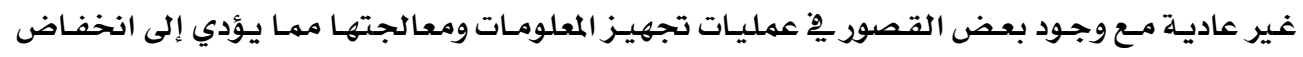

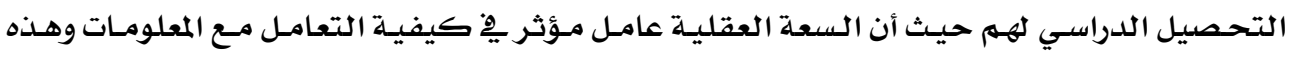

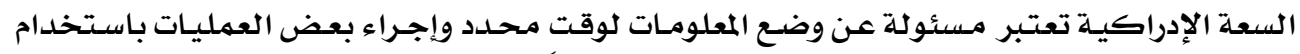

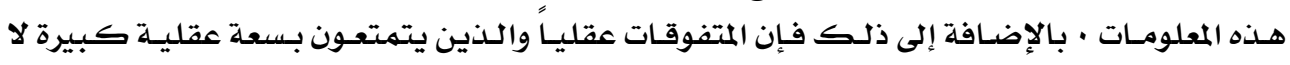

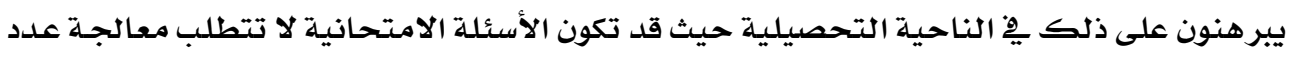

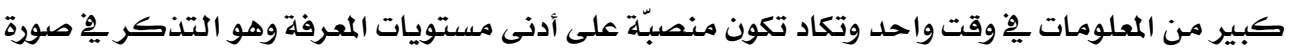

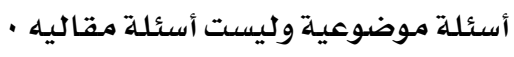

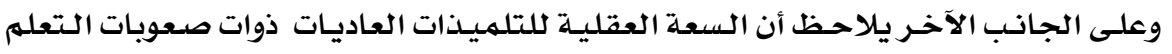

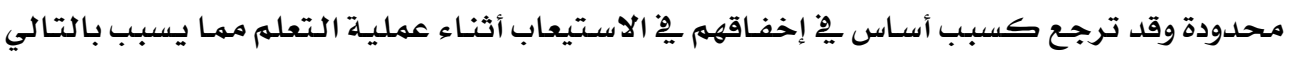

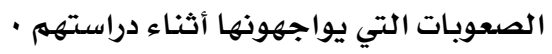




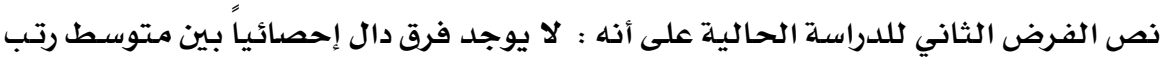

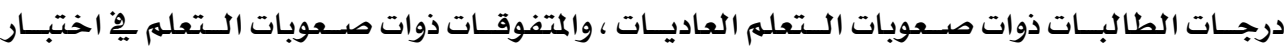

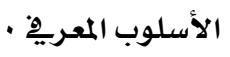

وللتحقـق مـن صـحة الفـرض قامست الباحثـة باسـتخدام اختبــار ( مـان وتنـى ) للمقارنـة بـين

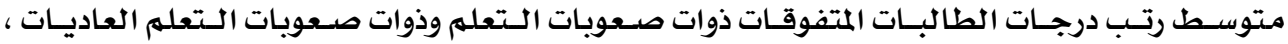
وجدول رقم (ع) يوضح هذه النتائج · مرجات الطلات

جدول ( ع )

الفروق بين العاديات والمتفوقات من ذوات صعويات التعلم بِ الأسلوب المعروِ2

\begin{tabular}{|c|c|c|c|c|}
\hline الدلالدة & قيمة " ى & متوسط الرتب & ن & المجموعة \\
\hline \multirow{2}{*}{.0 .0} & \multirow{2}{*}{ ד } & 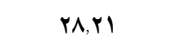 & r. & المتفوقات ذوات صعوبات التعله \\
\hline & & $10, \S 1$ & rr & العاديات ذوات صعوبات التعلم \\
\hline
\end{tabular}

النتائج الموضحة ِِِ جدول ( ع ) تشير إلى أنه يوجـد فرق بـين متوسط رتب درجـات مجموعـة

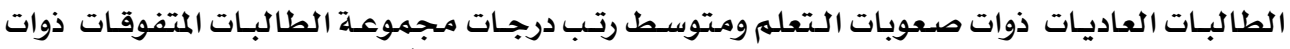

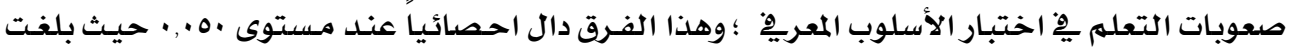

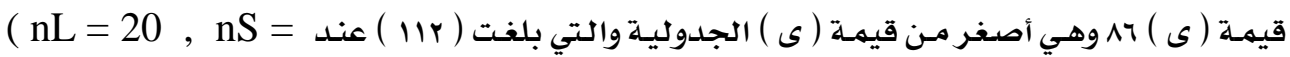

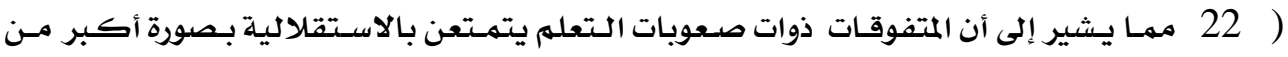

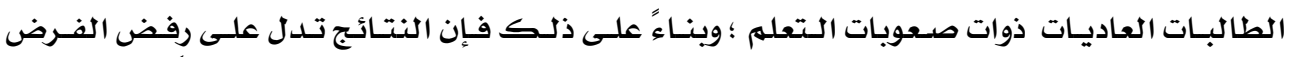

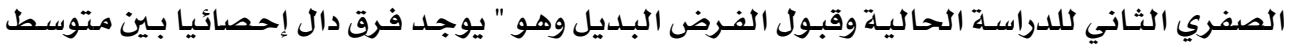

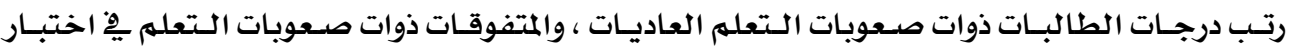
الأسلوب المعربِ داتِ

\section{رابعا : النتائج المتماقة بالفرض الثابث في الدراسة :}

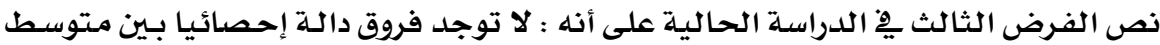

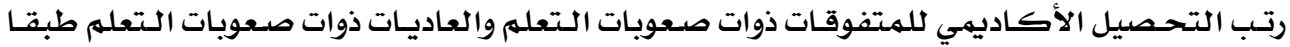

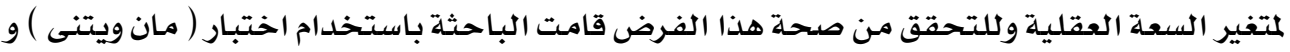

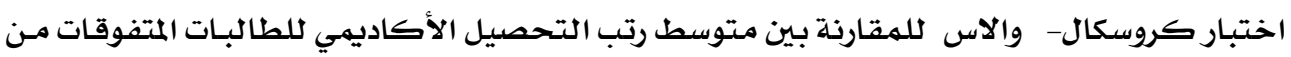

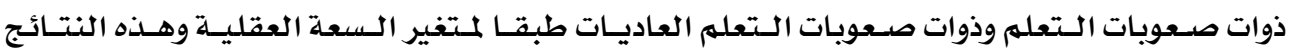

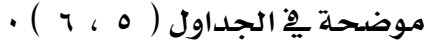


جدول ( ) ( )

\begin{tabular}{|c|c|c|c|c|}
\hline الدلالة & قيمة " ى & متوسط الرتب & ن & المجموعة \\
\hline \multirow{2}{*}{.0} & \multirow{2}{*}{09,0} & rr,o & r. & المتفوقات ذوات صعوبات التعلهم \\
\hline & & 11,0 & rr & العاديات ذوات صعوبات التعلم \\
\hline
\end{tabular}

ولتعرف قيم ودلالة هذه الفروق بين مجموعات البحث الأريعـة طبقا لمتغير السعة العقليـة ،

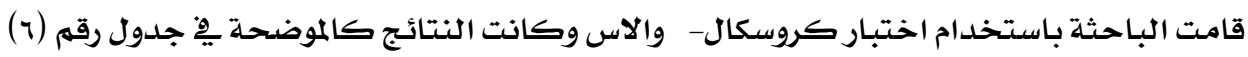

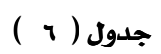

الفروق بين العاديات والمتفوقات من ذوات صعوبات التعلم بِ التحصيل الأكاديمي طبقا لمتفير السعة العقلية

\begin{tabular}{||c|c|c|l||}
\hline Mean Rank & N & VAR00016 & \\
\hline \hline 34.50 & 13 & 1.00 & \\
28.79 & 7 & 2.00 & \\
13.71 & 14 & 3.00 & VAR00015 \\
7.63 & 8 & 4.00 & \\
& 42 & Total & \\
\hline
\end{tabular}

\begin{tabular}{|c|c|}
\hline VAR00015 & \\
\hline 32.952 & Chi-Square \\
3 & df \\
.000 & Asymp. Sig. \\
\hline
\end{tabular}

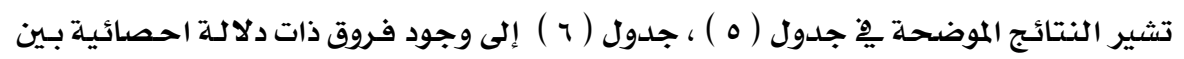

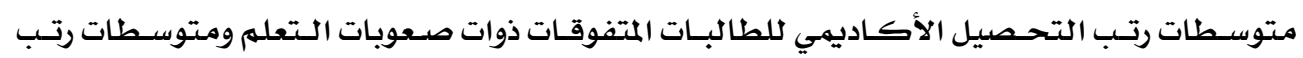

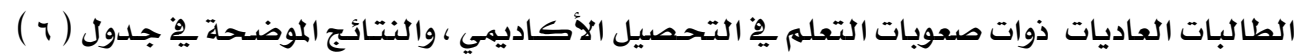

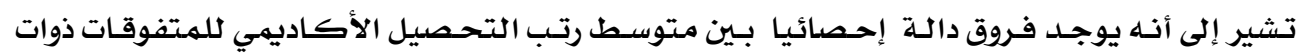

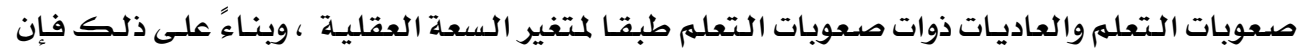

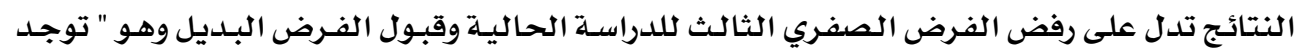

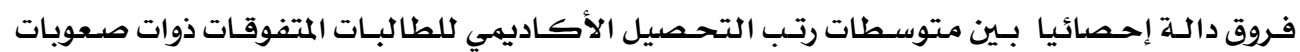

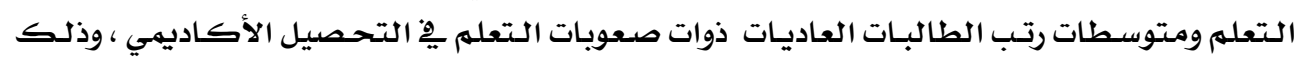
طبقا لمتغير السعة العقلية 


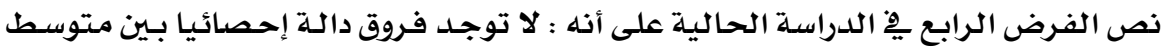

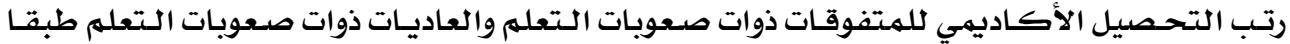

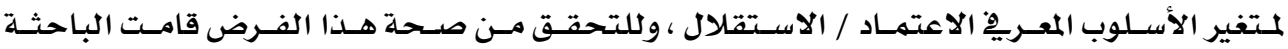

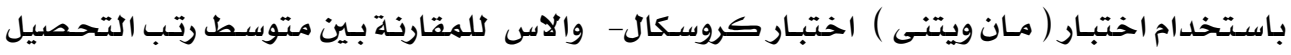

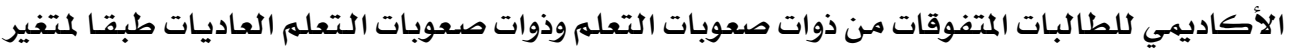

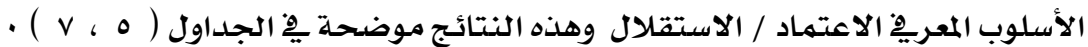

$$
\text { جدول ( ) }
$$

الفروق بين العاديات والمتفوقات من ذوات صعويات التعلم فِ التحصيل الأكاديمي طبقا لمتفير الأسلوب المعربِ

\begin{tabular}{|c|c|c|l||}
\hline Mean Rank & N & VAR00016 & \\
\hline \hline 35.21 & 12 & 1.00 & \\
28.44 & 8 & 2.00 & \\
15.75 & 12 & 3.00 & VAR00015 \\
6.40 & 10 & 4.00 & \\
& 42 & Total & \\
\hline
\end{tabular}

\begin{tabular}{|c|c|}
\hline VAR00015 & \\
\hline \hline 35.343 & Chi-Square \\
3 & df \\
.000 & Asymp. Sig. \\
\hline
\end{tabular}

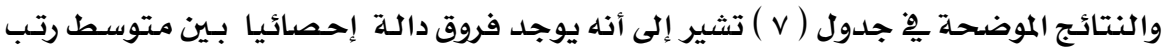

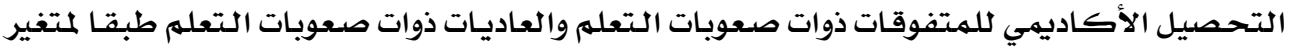

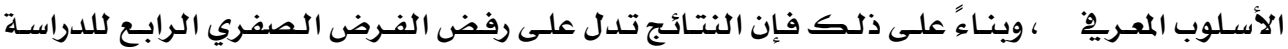

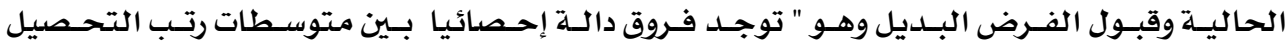

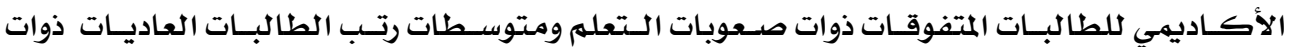

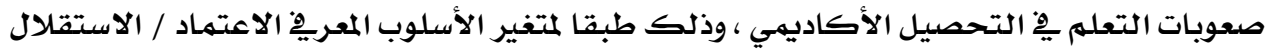

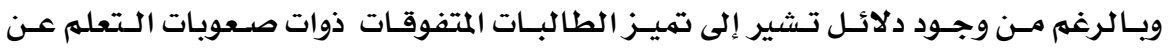

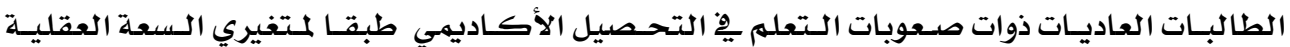

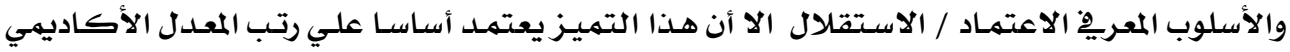

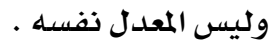


وياستعراض نتائج الدراسة الحالية يِّحدود العينة وأدوات الدراسة يمكن أن نخلص بما يلي :

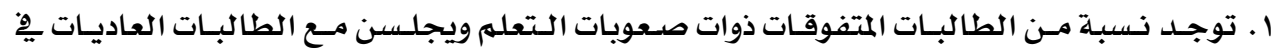

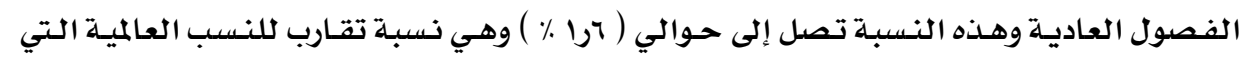

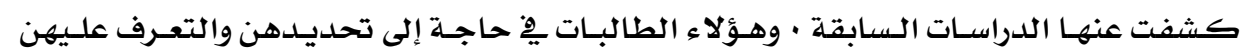

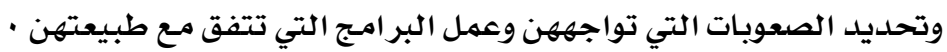

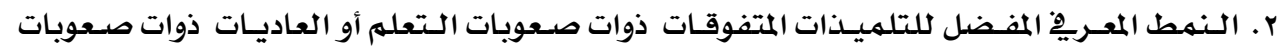

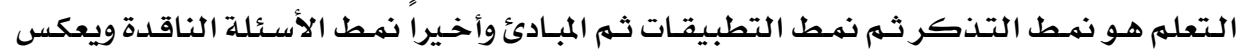

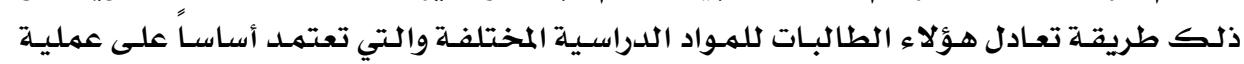

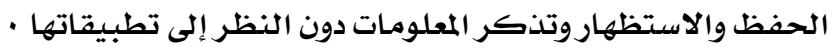

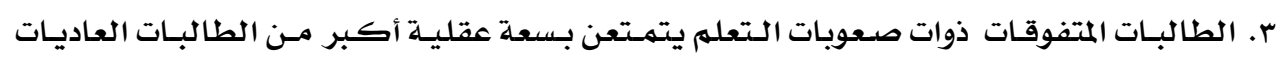

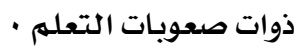

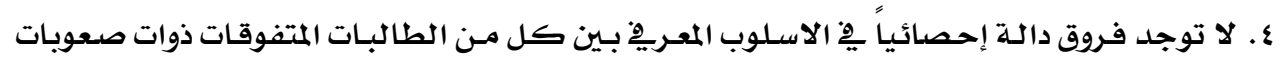

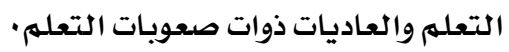

\section{وفي ضوى ذلك توصى الباحثة بعا يلي :}

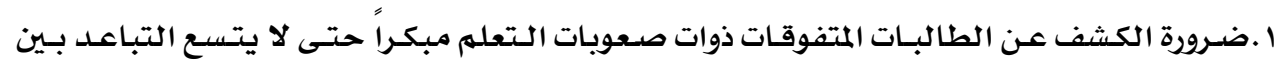

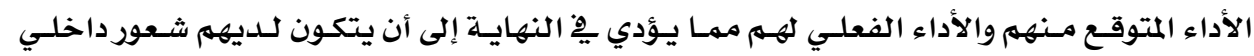

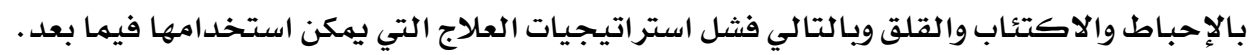

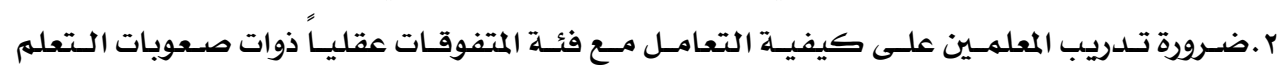

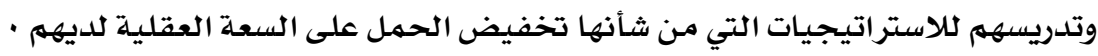

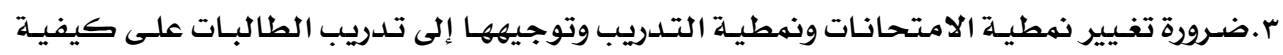

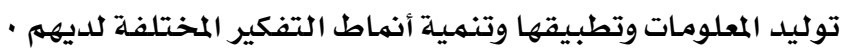

المراجع

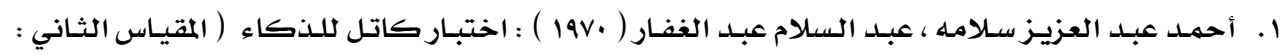

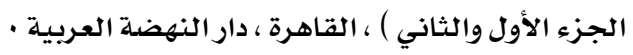

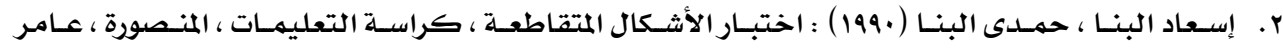
للطباعة والنشر.

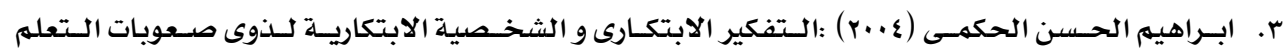

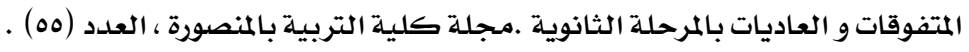

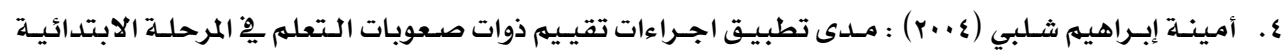

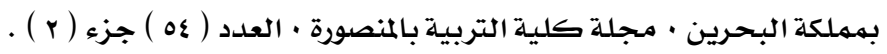




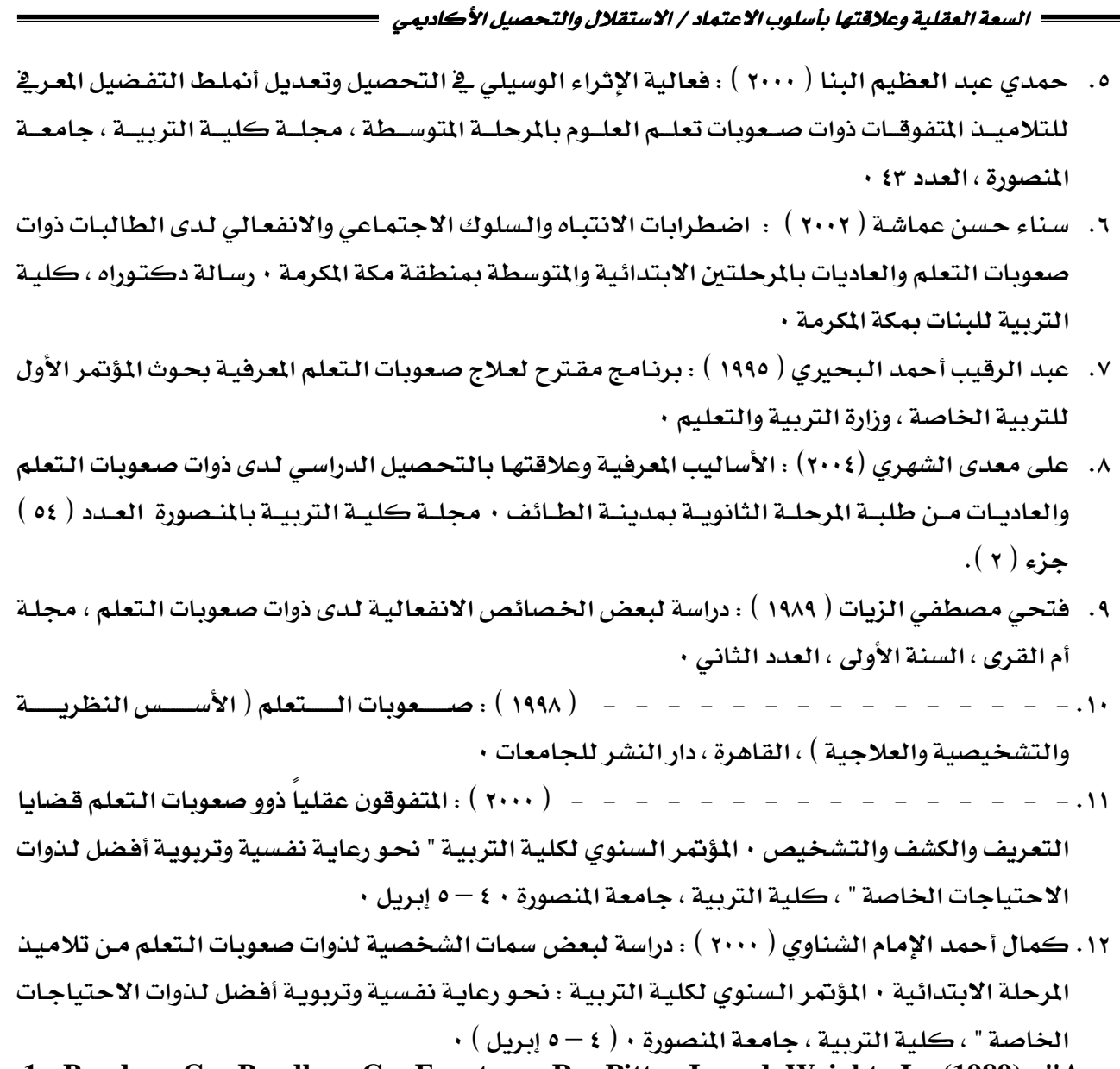

1- Boodoo, G.; Bradley, C.; Frontera, R,; Pitts, J. and Wright, L. (1989). "A survey of procedures used for identifying gifted learning disabled children.". Gifted Child Quarterly, 33 (3), 110-114.

2- Boodoo, G.; Bradley, C.; Frontera, R.; Pitts, J. and Wright, L. (1989). "A survey of procedures used for identifying gifted learning disabled children. ", Gifted Child Quarterly, 33 (3), 110-114.

3- Brody, L. \& Mills, C.(1997): Gifted children with learning disabilities: a review of the issues. Journal of learning Disabilities, 30 (3), 282-296.

4- Bryan, T. (1997): Assessing The personal and social status of students with learning disabilities, learning disabilities Research \& Practice, 12 (1) , 63 -76.

5- El-banna , H.: The development of a predictive theory of science education based upon information processing theory. $\mathrm{Ph}$, D. thesis, Glasgow University, 1987.

6- Mayes,S. D. ; Calhoun, S. L \& Crowell,F.W. (2000): Learning disabilities and ADHD: Overlapping Spectrum Disorders. Journal of learning Disabilities , 33 (5) , $417-424$. 


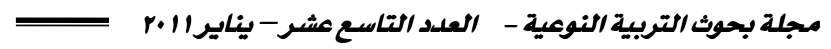

7- Scardamalia , M, : Information processing capacity and problem of horizontal decolage : a demonstration using combinatorial reasoning task. Child Development, 1989,60 (4),pp 973 -985.

8- Baum, S \& Owen, S (1988) : High ability? Learning disability students: How are they different ? Gifted Child Quarterly, 32,321-326.

9- Baum, S. M. (1990). "Gifted but learning disabled; a puzzling paradox.", (ERIC Document Reproduction Service No, ED: 469) .

10-Baum, S. M. (1994). 'Meeting the needs of gifted/learning disabled students: how far have we come?", Journal of Secondary Gifted Education, 5 (3), 6-22.

11-Beckley, D. (1998). "Gifted and learning disabled: twice exceptional students." (ERIC Document Reproduction Service No. ED: 424711).

12-Bees, C. (1998). The GOLD program: a program for gifted learning disabled adolescents.", Roeper Review, 27 (2), 155-161.

13-Brown-Mizuno, C. (1990). "Success strategies for learners who are learning disabled as well as gifted.", Teaching Exceptional Children, 23(1), 10- 12.

14-Case, R. (b) : Mental strategies, mental capacity and instruction : a neo Piagetion investigation. Journal of Experimental Child Psychology. 1974, 18,pp. 382-397

15-Case, $R$ (a) : Structures and strictures, some functional limitations on the course of cognitive growth. Cognitive Psychology, 1974,6, 544' 523.

16-Cohen, L. and Holliday, M. (1979). Statistics for education and physical education. London, Harper \& Row Ltd .

17-Ellsion, T. (1993). "Gifted and learning disabled ... a paradox?". Gifted Child Today, 16(1), 17-19.

18-Johnstone , A. H. and El- banna , H. : Understanding learning difficulties - a predictive research model. Studies in Higher Education. 1989,14 (2), pp. 159 168.

19-Levine, D. M. \& Reed, M. (1999): Developmental variation and Learning Disorders. ( sec. Ed). Educators Publishing service, inc. Cambridge, MA.

20-Pascual - Leon 'e , J. : A mathematical model for the transition rule in Piaget's developmental stages . Acta Psychologica, 1970, 32, pp. 302- 345.

21-Suter, D. P., and Wolf, J. S, (1987). "Issues in the identification and programming of the gifted / learning disabled child.", Journal for the Education of the Gifted, 10 (3), 227-237. 